University of Louisville

ThinkIR: The University of Louisville's Institutional Repository

Electronic Theses and Dissertations

$5-2009$

\title{
The role of glycogen synthase kinase 3-beta in interferon beta biology.
}

Huizhi Wang 1975-

University of Louisville

Follow this and additional works at: https://ir.library.louisville.edu/etd

\section{Recommended Citation}

Wang, Huizhi 1975-, "The role of glycogen synthase kinase 3-beta in interferon beta biology." (2009). Electronic Theses and Dissertations. Paper 1516.

https://doi.org/10.18297/etd/1516

This Doctoral Dissertation is brought to you for free and open access by ThinkIR: The University of Louisville's Institutional Repository. It has been accepted for inclusion in Electronic Theses and Dissertations by an authorized administrator of ThinkIR: The University of Louisville's Institutional Repository. This title appears here courtesy of the author, who has retained all other copyrights. For more information, please contact thinkir@louisville.edu. 


\title{
THE ROLE OF GLYCOGEN SYNTHASE KINASE 3-BETA IN INTERFERON BETA BIOLOGY
}

\author{
By \\ Huizhi Wang \\ B.S.M., Henan Medical University, CHINA, 1998 \\ M.S., ZhengZhou University, CHINA, 2001
}

\author{
A Disseration \\ Submitted to the Faculty of the \\ Graduated School of the University of Louisville \\ in Partial Fulfillment of the Requirements \\ For the Degree of \\ Doctor of Philosophy \\ Department of Microbiology and Immunology \\ University of Louisville \\ Louisville, KY \\ May 2009
}


THE ROLE OF GLYCOGEN SYNTHASE KINASE 3-BETA IN INTERFERON BETA BIOLOGY

\author{
By
}

Huizhi Wang

A Dissertation approved on

April 16, 2009

By the following Dissertation Committee

Michael Martin

Thomas C. Mitchell

Jill Suttles

David A. Scott

James W. Lillard

Pascale Alard 


\section{DEDICATION}

I would like to dedicate this dissertation to my beloved wife, Shaohua Liao, and my amazing children, Andrew and Matthew, who have always been there for me and have provided me endless support and encouragement. 


\section{ACKNOWLEDGEMENTS}

I would like to first thank my mentor, Dr. Michael Martin, for giving me the opportunity to work in his lab and to finish my projects satisfactorily. As the best mentor I have met, he always guided me with his suggestions, encourag me to think independently, and has been supportive even when my experiments were not working. He has always allowed me the freedom to arrange my working time and set up additional experiments I like, a luxury I understand is not afforded to many graduate students. He often works in the lab with us fellow students in the laboratory, giving us a feeling of comradeship. Besides being an outstanding mentor, he has been my friend and helped me like family or close friends would.

I owe great gratitude to my committee members, Drs. Tom Mitchell, David Scott, Jill Suttles, Pascale Alard, and James Lillard not only for their comments on my work in every committee meeting, but also for their cordial encouragement, invaluable help, and positive response. This was encouraging to me in my early years when I was a beginner and had very little confidence in my scientific acumen. I would especially like to express my gratitude to my co-mentor, Dr. Mitchell, for providing me with the knock-out mice which were indispensable for my project as well as his comments and suggestions on how to write my thesis and organize my less-connected data. 
I would also like to thank my classmate Xinyan Qu for her great help in my experiments and good advice. I also thank Dr. Manjunatha Benakanakere, Juhi Bagaitkar and Wenliang Zhang for their assistance in the experiments, as well as Kunal Rehani for his comradely help and great advice for the future career. Also special thank Jayme Martin for ordering our much-needed reagents and organizing other stuff in the lab.

I would also thank particularly Drs. Kinane, David Scott, Juhi Bagaitkar, Yunan Tang, Xinqin Kang, Juan Han, Zhen Gu and Ruqiang Liang for their generous help in my experiments. Certainly, I am also grateful to my fellow lab mates, Dr. Carlos Garcia for his help on numerous occasions in teaching lab techniques, critically reviewing my manuscript, teaching me how to analyze my data and correct my funny English, especially, "touting" his great ideas to me, while the unbelievable thing is most of his ideas eventually were proved correct.

I am also indebted to and my family in CHINA, my sister LiGuo Wang, my brother in law GuoBin Chen and my parents (Zhensheng Wang and YuChan Wang). They always wish me the best and give me years of support. Thanks for always having faith in me.

Finally, I would give my special thanks to my wife Shaohua Liao, my old son Andrew and my young son Matthew. It is because of their years of un-conditional support, enormous patience and love that always encouraged me and gave me the inspiration in this arduous learning journey. 


\title{
ABSTRACT \\ THE ROLE OF GLYCOGEN SYNTHASE KINASE 3 BETA IN INTERFERON BETA BIOLOGY
}

\author{
Huizhi Wang
}

April 16, 2009

It has been shown that GSK3 $\beta$ plays a critical role in the inflammation response by differentially regulating MyD88-dependent pro- and anti-inflammatory cytokines production in TLR4-stimulated innate immune cells. The work included in this dissertation demonstrates that (I) GSK3 $\beta$ negatively regulates the production of the TLR4 dependent and MyD88-independent cytokine, IFN $\beta$, by controlling the levels of total cJun and thereby modulating the amount of c-Jun /ATF2 complexes, and (II) that IFN $\beta$ induces IL-10 in dendritic cells by regulating GSK3 $\beta$ activity.

Part I: TLR4 stimulation of macrophages has been shown to induce the production of interferon- $\beta$ (IFN- $\beta$ ) via the MyD88-independent pathway. Here we demonstrate that glycogen synthase kinase $3-\beta($ GSK3- $\beta$ ) plays a fundamental role in this process. Suppression of GSK3- $\beta$ activity by pharmacological inhibition, siRNA-mediated gene silencing, or ectopic expression of a kinase-dead GSK3- $\beta$ mutant, augmented IFN- $\beta$ production by TLR4-stimulated macrophages. Conversely, ectopic expression of a constitutively active GSK3- $\beta$ mutant severely attenuated IFN- $\beta$ production. GSK3- $\beta$ was found to negatively control the cellular levels of the transcription factor c-Jun and its nuclear association with ATF-2. siRNA-mediated knockdown of c-Jun levels abrogated 
the ability of GSK3- $\beta$ inhibition to augment IFN- $\beta$ production by TLR4 stimulated macrophages. Inhibition of GSK3 in vivo resulted in potently augmenting the systemic levels of IFN- $\beta$ in mice that were administered LPS. These findings identified a novel regulatory pathway controlling IFN- $\beta$ production by TLR4-stimulated innate immune cells.

Part II: IFN- $\beta$ is known to induce the production of IL- 10 by innate immune cells, yet the underlying cellular mechanisms responsible for this effect are unknown. Here, we demonstrate that the constitutively active serine/threonine kinase, GSK3- $\beta$, controls the IFN- $\beta$-mediated production of IL-10 by human dendritic cells. Stimulation of cells with IFN- $\beta$ induced the activation of the phosphatidylinositol 3-kinase (PI3K) pathway and blockade of PI3K activity inhibited the ability of IFN- $\beta$ to induce IL-10 production. Assessment of downstream kinases within the PI3K pathway demonstrated that IFN- $\beta$ induced the phosphorylation and subsequent suppression of GSK3 $\beta$ activity. Direct inhibition of GSK3 activity via pharmacological inhibition, siRNA-mediated knockdown of GSK3- $\beta$, or ectopic expression of a kinase dead GSK3- $\beta$ potently augmented the levels of IL-10 produced by type I IFN-stimulated dendritic cells, whereas no affect on the production of pro-inflammatory cytokines was observed. In contrast, ectopic expression of a constitutively active GSK3- $\beta$ mutant severely attenuated the levels of IL10 produced by IFN- $\beta$-stimulated cells. Analysis of transcription factors involved in the regulation of IL-10 showed that IFN- $\beta$ increased the nuclear levels of phospho-CREB and this effect was dependent upon the ability of IFN- $\beta$ to induce PI3K activity and inactivate GSK3- $\beta$. These findings identify the cellular mechanism by which IFN- $\beta$ induces IL-10 production by innate immune cells. 


\section{TABLE OF CONTENTS}

PAGE

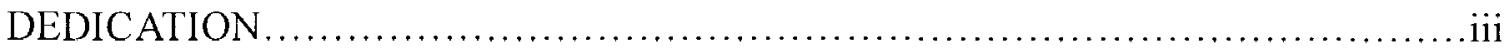

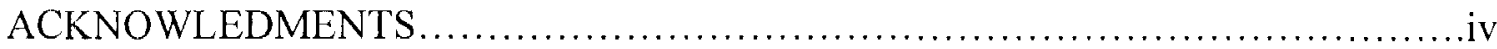

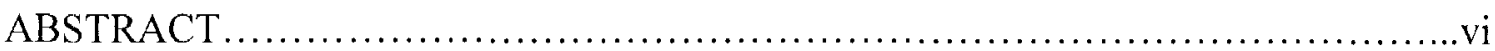

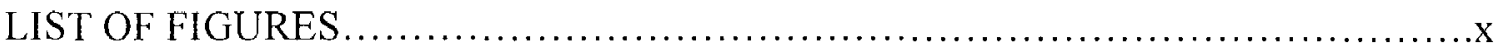

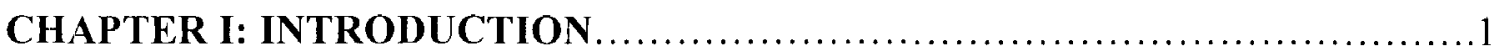

CHAPTER II: INTERFERON BETA PRODUCTION BY TLR4-STIMULATED

INNATE IMMUNE CELLS IS NEGATIVELY REGULATED BY GSK3 BETA.. 12

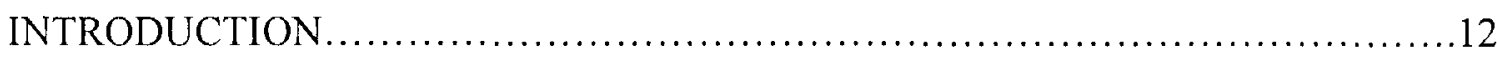

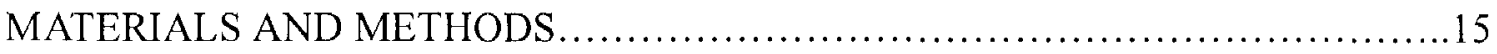

RESULTS

TLR4-mediated phosphorylation of GSK3 3 (S9) occurs in the absence of MyD88

GSK $3 \beta$ negatively regulates TLR4-induced IFN- $\beta$ production 18

GSK3 controls the nuclear levels of c-Jun/ATF-2 complexes by regulating total cJun levels.

GSK3 inhibits TLR-4 induced IFN- $\beta$ production by regulating c-Jun levels.....21

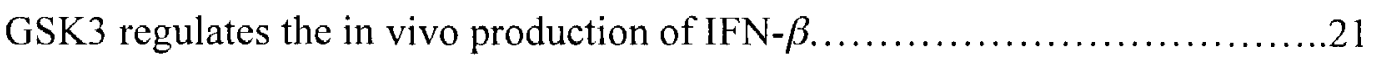

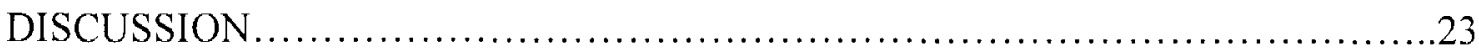




\section{CHAPTER III: INTERFERON BETA INDUCES IL-10 PRODUCTION BY}

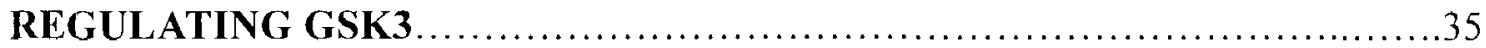

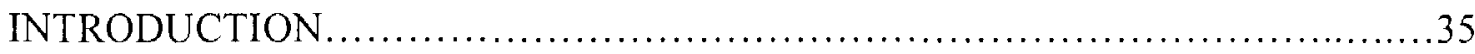

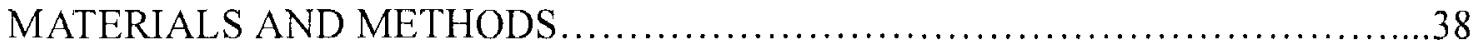

RESULTS

LPS-mediated IFN- $\beta$ enhances IL-10 production from DCs $\ldots \ldots \ldots \ldots \ldots \ldots \ldots . \ldots 42$

IFN- $\beta$-activates PI3K pathway and mediates the subsequent inactivation of GSK3- $\beta$

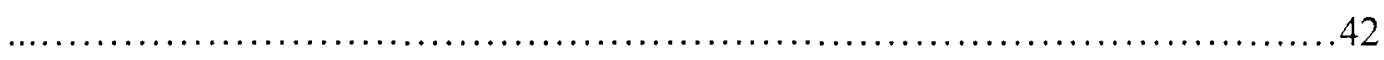

IFN- $\beta$ induces IL-10 production from DCs by regulating GSK3- $\beta$ activity $\ldots \ldots . .43$

IFN- $\beta$ induces partial but not complete inactivation of GSK3- $\beta$ activity $\ldots \ldots \ldots . . .45$

IFN- $\beta$ enhances the activity of the transcriptional factor CREB ..................45

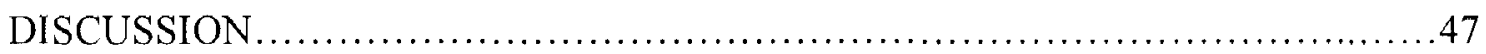

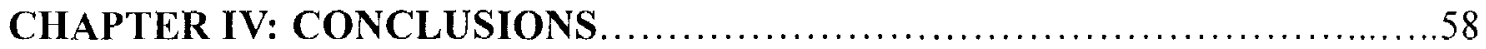

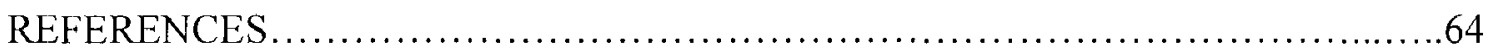

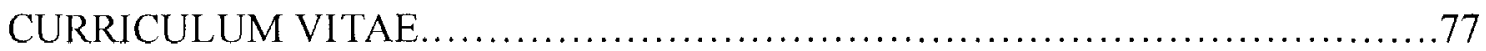




\section{LIST OF FIGURES}

PAGE

1. Stimulation of macrophages with LPS induces the phosphophorylation of GSK3- $\beta$

(S9) in both wild-type and MyD88-deficiency macrophages..... .27

2. GSK3 negatively controls IFN- $\beta$ production by LPS-stimulated macrophages........28

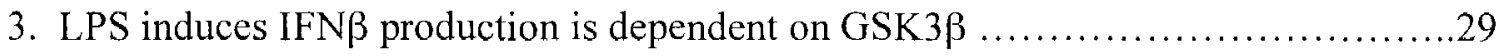

4. GSK3 negatively affects the levels of nuclear c-Jun/ATF2 heterodimer complexes by

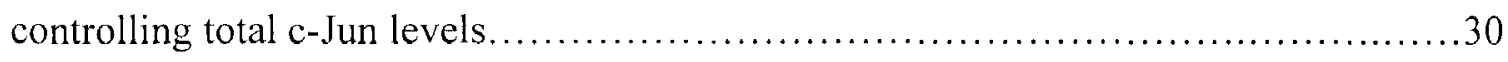

5. GSK3 has no discernible effect on the nuclear levels of the transcription NF- $\mathrm{KB}$ and

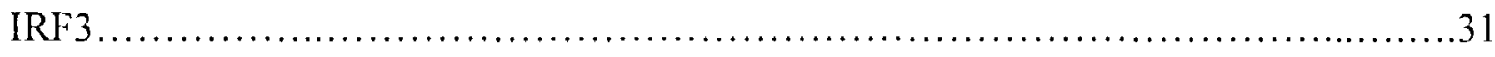

6. GSK3 controls IFN $\beta$ production by regulating c-Jun levels in LPS-stimulated

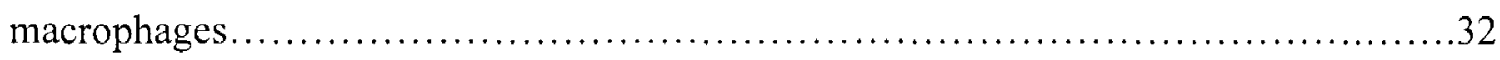

7. Inhibition of GSK3 augments the systemic levels of IFN $\beta$ in mice given LPS _......33

8. IFN $\beta$ is required for LPS-induced IL-10 production from DCs ...................50

9. IFN $\beta$ stimulation alone has no effect to the production of pro-inflammation cytokines

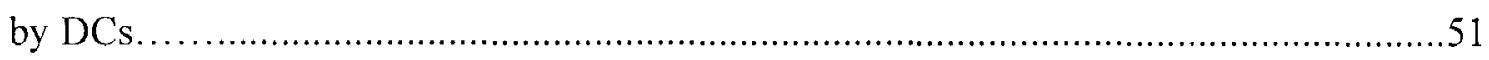

10. IFN- $\beta$ induces PI3K-dependent phosphorylation of Akt and GSK3 $\beta$ in DCs.......52

11. IFN $\beta$ induced inhibition of GSK $3 \beta$ is dependent on the PI3K activity .............53

12. Regulation of IFN- $\beta$ induced IL-10 production by PI3K and GSK3 $\ldots \ldots \ldots \ldots \ldots . \ldots 54$

13. IFN- $\beta$ induced IL-10 production is dependent on GSK3 $\beta$ activity .................55 
14. IFN- $\beta$ stimulation of DCs alters the phospho-levels of the GSK-3 $\beta$ substrates glycogen synthase and CREB

15. Model for the role of GSK $3 \beta$ in regulating the production of IFN $\beta$ by TLR4

stimulated innate immune cells. .34

16. Model for the role of GSK $3 \beta$ in regulating IL-10 production by IFN $\beta$ stimulated DCs. 


\section{CHAPTER I}

\section{INTRODUCTION}

\section{Innate Immunity}

The immune system of vertebrates consists of two broad components that comprise innate and adaptive immune immunity. The innate immune system is an ancient form of host defense and is conserved in all multicellular organisms (1). As the first line of defense against microbial pathogens, the innate immune system of mammals consists of surface barriers, humoral factors, macrophages, NK cells, and dendritic cells (DCs) (2). Upon microbial invasion, distinct families of pattern-recognition receptors (PRRs) initiate intracellular signaling events that link the recognition of a pathogen to the nuclear transcription of host defense genes. The most widely studied and characterized PRRs include Toll-like receptors (TLRs) that recognize highly conserved molecular patterns derived from bacteria, viruses, protozoa and fungi (3). These receptors recruit adaptor molecules that create multi-protein platforms that then recruit and/or activate downstream kinases. These events, among others, lead to the engagement of several signaling pathways culminating in activation of nuclear transcription factor kappa $\mathrm{B}(\mathrm{NF}-\mathrm{\kappa} \mathrm{B})$, mitogen-activated protein kinase (MAPK), and interferon regulatory factors (IRFs) that control the transcription of genes encoding inflammatory cytokines and type I interferon, which are important for eliminating invading pathogens. 
Toll was originally identified as receptor that is expressed by insects and was found to be essential for establishing dorsoventral polarity during embryogenesis (4). Subsequent studies revealed that Toll also played an essential role in the insect innate immune response against fungal infections (5). Homologues of Toll identified through database searches have identified at least 13 members of TLRs (6). TLR1-9 are common to humans and mice. TLR10 appears to be functional only in humans, whereas TLR11-13 have been found in mouse and less characterized (7-9). Each TLR appears to recognize distinct PAMPs derived from various microorganisms including bacteria, viruses, protozoa and fungi. TLRs are classified as type I transmembrane proteins characterized by an ectodomain composed of leucine rich repeats (LRR) that are responsible for recognition of PAMPs and a cytoplasmic domain homologous to the cytoplasmic region of the IL-1 receptor, known as the TIR domain, which is required for downstream signaling (10). TLRs are classified into several groups based on the types of PAMPs they recognize. The first class contains TLR1, 2, 4 and 6 which recognize lipids. For example, TLR4, together with its extracellular components such as MD-2 and CD14, recognizes lipopolysaccharide (LPS) from Gram-negative bacterial. TLR2 forms heterodimers with TLR1 or TLR6, as well as non-TLRs such as CD36 to discriminate among a wide array of PAMPs, including peptidoglycan, lipopeptides and lipoproteins of Gram-positive bacteria, mycoplasma lipopeptides and fungal zymosan (11). In addition, human TLR10 is thought to complex with TLR2 and TLR1, although a ligand for this complex remains unknown. The second class of TLRs contains TLR5 and TLR11 and recognize protein ligands (12-14). TLR5 is expressed abundantly in intestinal CD11cpositive lamina propria cells where it senses bacterial flagellin (15). Mouse TLR11 
recognizes an unknown component(s) of uropathogenic bacterial, and a profilin-like molecule of the protozoan parasite Toxoplasma gondii $(16,17)$. The third class of TLRs includes TLR3, 7, 8 and 9, which are localized intracellularly where they detect nucleic acids derived from viruses and bacteria $(18,19)$. TLR3 was shown to recognize double stranded RNA (dsRNA), which is produced by many viruses during replication. TLR7 recognizes synthetic imidazoquinoline-like molecules, guanosine analogs, single stranded RNA (ssRNA) derived from various viruses and small interfering RNA (20). Human TLR8 is similar to TLR7 in that it recognizes imidazoquinolines and ssRNA (20). However, the ligands of mouse TLR8 are unknown. TLR9 recognizes CpG DNA motifs present in bacterial and viral genomes as well as non-nucleic acids such as hemozoin from the malaria parasite (11).

Lipopolysaccharide (LPS), a membrane glycolipid of Gram-negative bacteria, is a mediator of inflammation (21). The ability of the TLR4 complex to recognize LPS depends upon several additional extracellular molecules including lipid-binding protein (LBP), CD14 and MD-2 that associate with TLR4 $(22,23)$. Lipid-binding protein (LBP), a plasma protein that binds the lipid A moiety of LPS and forms a complex that can lead to the recruitment of another LPS-binding molecule, CD14 (21). Subsequent studies have identified that MD-2 is critical for optimal LPS-mediated NF- $\kappa$ B activation as well as surface expression of TLR4 (24). Upon activation of TLR4 by LPS, the Toll/Interleukin-1 receptor (TIR) domain, a conserved intracellular domain shared by all TLRs, recruits the adaptor, myeloid differentiation 88 (MyD88), which can then lead to the activation of several signal transduction that mediate various aspects of host defense $(25,26)$. 
Stimulation of the TLR4 complex by LPS can trigger a potent inflammatory response that can be classified as MyD88-dependent or MyD88-independent (27). The adaptor protein MyD88 is utilized by most TLRs (except TLR3) to initiate the host inflammatory response via the recruitment of various downstream signaling molecules including IRAK-4, IRAK-1, TRAF6, and activation of the NF-kB complex (28). Although MyD88 plays a critical role in mediating the production of most pro- and antiinflammatory cytokine production, studies using mice deficient in MyD88 have demonstrated the existence of a MyD88-independent pathway that regulates the production of type 1 interferons, including IFN- $\alpha$ and IFN- $\beta$ upon TLR3- or TLR4stimulation $(29,30)$. This is characterized by delayed activation of NF-KB, MAPK(30), production of IFN- $\alpha / \beta$, Stat 1 (Tyr701), RANTES, IP-10 (27), and the upregulation of costimulatory molecules. In this regard, studies by two laboratories demonstrated that the TIR-containing adaptor protein TRIF was responsible for the activation of the TLR4mediated MyD88-independent pathway $(31,32)$. Furthermore, the ability of TLR4 to induce type I interferon in the absence of MyD88 has been shown to be dependent upon the recruitment of an additional adaptor molecule called TRIF-related adaptor molecule (TRAM) (33). The regulation of many MyD88-independent responses, including type I interferons, has been shown to be critically dependent upon the transcription factor IRF3. IRF3 is ubiquitously expressed in an inactive form in the cytoplasm (28). Upon TLR4signaling, TBK-1 and IKK-ع have been shown to phosphorylate IRF3 on specific serine residues and are believed to function as the IRF3 kinases $(34,35)$. Indeed, upon phosphorylation, IRF3 undergoes homodimerization, translocates to the nucleus, associates with and activates a transcriptional complex involving the nuclear co-activator 
of transcription $\mathrm{CBP} / \mathrm{p} 300$ that initiates the transcription of type I IFNs (36).

\section{The PI3K pathway and function of GSK3 in the host inflammatory response}

Mammalian PI3Ks can be divided into three classes I, II, and III based on their primary sequences, mechanisms of regulation, and specificities of substrates they phosphorylate $(37,38)$. Class I PI3Ks exist as heterodimers consisting of one of four catalytic subunits $(\mathrm{p} 110 \alpha, \beta, \delta, \gamma)$ and one of two families of regulatory subunits $(\mathrm{p} 85 \alpha, \beta)$ (39). This class of PI3K acts on phosphatidylinositol 4,5-bisphosphate (PIP2) to produce phosphatidylinositol 3,4,5-trisphosphate (PI(3,4,5)P3 (PIP3), and this process is reversed by the phosphatase PTEN that converts PIP3 to PIP2 (40). Class II PI3Ks phosphorylate phosphatidylinositol and phosphatidylinositol 4-phosphate and class III PI3Ks phosphorylate only phosphatidylinositol to generate phosphatidylinositol 3-phospate (37). The PI3K pathway has been shown to be activated by various TLR ligands and can function as a positive or negative regulator of TLR responses depending on the cell type and the TLR agonists used (41). Of the multiple forms of phosphatidylinositol-3 kinases, the class $I_{A}$ PI3K consists of heterodimers made up of a p85 regulatory and a p110 catalytic subunit (42). Cytoplasmic PI3K can bind to and associate with phospho-receptor tyrosine kinase residues as well as adaptor molecules at the plasma membrane (42). Upon activation, PI3K phosphorylates and converts plasma lipid membrane phosphatidyl inositol 4,5-biphosphate $\left(\mathrm{PIP}_{2}\right)$ to phosphatidyl inositol 3,4,5-triphosphate $\left(\mathrm{PIP}_{3}\right)$ which will recruit signaling proteins containing pleckstrin-homology (PH) domains like Akt,

PDK1 and PDK2 (42). Association with PDK1/2 leads to the phosphorylation of Akt. Dual phosphorylation of Akt (Thr308/Ser473) leads to full activation and its ability to 
subsequently phosphorylate downstream kinases, including the glycogen synthase kinase $3 \beta(\operatorname{GSK} 3 \beta)(43)$.

GSK3 is a multifunctional serine/threonine kinase within the PI3K pathway and has been identified in all eukaryotic organisms (44). Although initially named due to its ability to phosphorylate glycogen synthase, GSK3 has subsequently been demonstrated to phosphorylate more than 40 different substrates (45). Thus, GSK3 activity can affect a number of different cellular processes and has been implicated in human diseases like Alzheimer's disease, diabetes, and various cancers (46). There are two highly homologous forms of GSK3 protein, GSK3 $\alpha$ and GSK $3 \beta$, which are critical factors involved in the regulation of a wide variety of signaling proteins and transcription factors including c-Jun, c-myc, cAMP response element binding protein, cyclin D1, cyclin E $\beta$ catenin and NF-AT (47). Despite their homology, GSK3 $\alpha$ and GSK3 $\beta$ are not functionally redundant, as mice deficient in the beta isoform die on embryonic day 16 due to liver degeneration while the alpha isoform cannot compensate for this deficiency (48). GSK3 is a constitutively active kinase but can be inactivated by site specific serine phosphorylation (49). Phosphorylation GSK3 $\beta$ at Ser9 or GSK $\alpha$ at Ser 21 causes the Nterminus of GSK3 occupy the priming site which impedes the substrate's accessibility to the active site of GSK3 (50). GSK3 does not auto-phosphorylate the Ser9/21 sites; Instead, other kinases like Akt (PKB), PKA, and P90RSK have been shown to phosphorylate GSK3, resulting in its inactivation (51) (52) (53). The consensus sequence for a GSK3 substrate is Ser/Thr-X-X-X-Ser/Thr, where the first Ser/Thr is the target residue for phosphorylation by GSK3 and $\mathrm{X}$ is any amino acid (54-56). Although GSK3 can phosporylate "non-primed substrates, if the second Ser/Thr has been phosphorylated 
by another "priming kinase", the efficiency of GSK3 phosphorylation is greatly increased.

Previous studies have demonstrated that the phosphatidylinositol-3 kinase (PI3K) pathway plays a fundamental role in regulating the host inflammatory response to a variety of TLR agonists (57-59). Our previous findings identified that the constitutively active serine/threonine kinase, glycogen synthase kinase 3 (GSK3), was the central kinase responsible for the ability of this pathway to differentially regulate the production of pro- and anti-inflammatory cytokines by TLR-stimulated innate immune cells (60). Moreover, we demonstrated that inhibition of GSK3 $\beta$ regulates the inflammatory response via enhanced activation of CREB (S133) which displaces NF- $\mathrm{kB}$ p65 from binding to the common transcription factor CREB-binding protein (CBP) (60). Although GSK3 $\beta$ plays a central role in regulating the production of MyD88-dependent cytokines, the ability of GSK3 to influence MyD88-independent cytokines, i.e. interferon beta (IFN $\beta$ ), and whether GSK3 $\beta$ plays a functional role in the IFN $\beta$ signaling pathways induction of IL-10 are still largely unknown. Therefore, the work described in this dissertation focused on answering these two questions.

\section{Induction of Interferon beta (IFN $\beta$ ) and its regulation}

IFN $\alpha / \beta$ are classified as type I interferons (IFNs) (61) and have been extensively used to treat a variety of human diseases including multiple leukemia, chronic hepatitis B and $\mathrm{C}(62-64)$. Moreover, IFN- $\beta$ has been regarded as the first choice for the initial treatment of relapsing remitting multiple sclerosis (MS)(65-67). Macrophages have been shown to be a major cellular source of IFN- $\alpha / \beta$ in the immune system, however, it has 
also been demonstrated that IFN $\beta$ can be produced by other immune cells including, dendritic cells, fibroblasts, NK cells, and T cells in response to both pathogen nucleic acids and bacterial cell wall components such as lipopolysaccharide (LPS) (68). In innate immune cells, pattern-recognition-receptors (PRRs) are involved in the induction of IFN $\beta$, including Toll-like receptors (TLRs) and RIG-I-like receptors (RLRs). Five TLRs (TLR3, TLR4, TLR7, TLR8, TLR9) have been shown to potently promote type I IFNs (69). Four of these TLRs, TLR3, TLR7, TLR8, and TLR9, can be stimulated by nucleic acid agonists produced during viral or bacterial infections (70). Specifically, TLR3 can be activated by double stranded RNA (71); TLR7 and TLR8 (in humans only) can be activated by antiviral derivatives of nucleoside-like imidazoquinoline $(72,73)$, loxoribine (74) and GU-rich single-stranded (ss) RNAs (75-77). TLR9 can be activated by nonmethylated double-stranded (ds) CpG-rich DNA $(78,79)$. TLR4, which recognizes LPS, can also induce the production of type I IFNs (80-82).

The production of Type I IFNs has been demonstrated to be regulated at multiple steps, which include cellular processes involved both transcriptional and posttranslational mechanisms (83-85). The enhancesome of interferon beta is the best model to understand the multiple levels of regulation involved in the production of type I IFNs. A multi-protein complex called an enhanceosome is assembled at the IFN $\beta$ promoter in response to a viral or bacterial challenge (86). The enhanceosome consists of at least three families of transcription factors $-\mathrm{ATF}-2 / \mathrm{c}-\mathrm{Jun}$, nuclear factor (NF)- $\mathrm{kB}$ and interferon regulatory factor (IRFs). Of these, the activities of NF- $\mathrm{KB}$ and IRF3 are regulated by their subcellular localization and site-specific phosphorylation $(87,88)$. In the inactive state, NF- $\mathrm{kB}$ is held in the cytosol by inhibitory $\kappa \mathrm{B}(\mathrm{I} \kappa \mathrm{B})$ family members 
(89). Upon cellular stimulation, such as IL-1 $\beta, T N F-\alpha$, and bacterial or viral components, the I $\mathrm{KB}$ kinase (IKK) is activated and phosphorylates I $\mathrm{B}$. Once phosphorylated, I $\mathrm{K} \mathrm{B}$ is ubiquitinated and subsequently degraded by the proteasome (89), free NF- $\mathrm{KB}$ then translocates into the nucleus and turns on its target genes. Similar to NF- $\mathrm{kB}$, the inactive form of IRF3 is also cytosolic. In response to a bacterial or viral challenge, IRF3 is phosphorylated by the IKK-like kinases TBK-1 and IKKe $(34,35)$. Phosphorylation of IRF3 leads to its dimerization and translocation into the nucleus. Viral infection also leads to activation of stress kinases such as JNK and p38 kinase, which phosphorylate ATF2/c-Jun in the nucleus (90). Together, with the nuclear architectural protein HMG-I (Y), NF-KB, IRF3 and ATF2/c-Jun assemble into a stereo-specific enhanceosome complex that remodels the chromatin within the promoter region of IFN $\beta$, resulting in its transcriptional initiation $(91,92)$.

\section{Type I IFN signaling and IL-10 production}

All type I IFNs are genetically and structurally similar and utilize the same receptor, IFNAR, that is composed of two subunits, IFNAR1 and IFNAR2 (93). Both subunits are necessary for most IFN-mediated cellular functions and if either of them is deficient, there is no high-affinity ligand binding and little to no biological effects (94). Type I IFNs have been shown to have a variety of cellular properties including antiviral, anti-proliferation, induction of apoptosis, and immunoregulation of both the innate and adaptive immune compartments $(94,95)$. Recently, type I IFNs have also been demonstrated to exert potent anti-inflammatory properties (96).

The major intracellular signaling pathway used by Type I IFNs is the Janus 
kinase-signal transducers and activators of transcription pathway (JAK-STAT) (97). IFNARI and IFNAR2 constitutively bind to a single specific member of the Janus Kinase (JAK) family, Tyk2 and Jak1, respectively (97). Ligand binding induces the phosphorylation of Jak1 and Tyk2, which leads to the activation of signal transducer and activator of transcription 1 (STAT1) and STAT2 to form a STAT1:STAT2 heterodimer that associates with the transcription factor interferon regulatory factor 9 (IRF9) to form a complex which binds to IFN-stimulated response elements (ISREs) present in the promoters of many IFN-stimulated genes (ISGs) (94), thereby inducing gene transcription.

IL-10 has been shown to be a prototypical immunosuppressive cytokine produced by $T$ cells, B cells, dendritic cells, and monocytes/macrophages (98). Interestingly, type I IFNs have been reported to play a crucial role in regulating the production of IL-10 by innate immune cells $(99,100)$. Previous studies by Chang et al. have demonstrated the fundamental role IFN- $\beta$ plays in regulating the levels of IL-10 produced by Toll-like receptor (TLR)-stimulated innate immune cells (101). Several other studies have additionally shown that IFN- $\beta$ can modulate the immune response to other cellular stimuli by positively controlling the production of IL-10 (102-104). Due to their immunomodulatory properties, type I IFNs have also been studied extensively for the initial treatment of relapsing remitting multiple sclerosis (MS) (65-67). Although the precise therapeutic mechanism of action of IFN $\beta$ in MS treatment is unclear, IFN- $\beta$ treatment has been shown to increase the serum levels of IL-10 present in MS patients (100), and this effect is believed to play a fundamental role in the therapeutic value of type I IFNs in the treatment of MS patients (105). Despite the numerous reports linking 
IFN- $\beta$ to the induction of IL-10 production, the underlying cellular mechanisms responsible for the ability of IFN- $\beta$ to induce IL-10 production is unresolved.

The following chapters detail our studies on the functional role of GSK3 $\beta$ in TLR4-induced IFN $\beta$ production and its regulatory role in the IFN $\beta$ mediated signaling pathway. In the first part of my project, we demonstrated that GSK3 $\beta$ activity plays a fundamental role in controlling the production of the MyD88-independent cytokine, IFN$\beta$, by TLR4-stimulated innate cells and also defined the cellular mechanism by which GSK3 regulates the production of IFN $\beta$. In the second part of my project, we have elucidated and characterized how IFN $\beta$ signaling in innate immune cells is able to induce IL-10 production and have identified how this process is regulated at the transcriptional level. 


\section{CHAPTER II}

\section{INTERFERON-BETA PRODUCTION BY TLR4-STIMULATED INNATE IMMUNE CELLS IS NEGATIVELY REGULATED BY GSK3-BETA}

\section{Introduction}

Toll-like receptors (TLRs) are type I transmembrane receptors involved in the recognition of highly conserved microbial components (106). Activation of TLRs on innate immune cells can result in the recruitment of different downstream signaling adaptors that impart selectivity on the repertoire of cytokines produced (106). In this regard, the TLR4-signaling pathway can activate distinct innate immune responses via the recruitment of the adaptor molecules TIRAP-MyD88 or TRAM-TRIF $(32,33,107$, 108). The production of pro- and anti-inflammatory cytokines by TLR4-stimulated innate immune cells has been shown to be dependent upon signaling events initiated by TIRAP-MyD88 (107-109). In contrast, the recruitment of the adaptor molecules TRAM and TRIF mediate a signaling cascade involving the activation of the two non-canonical I $\mathrm{KB}$ kinases, $\mathrm{TBK}-1$ and $\mathrm{IKK}-\varepsilon$, as well as the phospho-specific post-translational modifications of the transcription factors NF- $\mathrm{BB}, \mathrm{ATF}-2 / \mathrm{c}-\mathrm{Jun}$, and IRF-3 that culminates in the production of type I interferons (IFNs), including IFN- $\beta(31-33,110)$. Although the molecular mechanisms regulating NF-אB and IRF-3 activity, as well as their involvement in controlling IFN- $\beta$ production by TLR4-stimulated innate immune cells 
have been well described, the upstream signaling events that regulate the levels and activity of the transcriptional complex, ATF-2/c-Jun, and the role this complex plays in controlling IFN- $\beta$ production by TLR4-stimulated cells is poorly understood.

Stimulation of TLR4 can activate the phosphatidylinositol-3 kinase (PI3K) pathway, which restrains the MyD88-dependent production of pro-inflammatory cytokines $(57,58,111)$. In the presence of MyD88, the ability of the PI3K pathway to negatively regulate the production of pro-inflammatory cytokines, while augmenting the levels of the anti-inflammatory cytokine, IL-10, is due to its ability to inactivate the constitutively active serine/threonine kinase, GSK3- $\beta$ in TLR4-stimulated cells $(58,60$, $112,113)$. The serine 9 mediated inactivation of GSK3- $\beta$ results in the alteration of the transcriptional complex involving the co-activator of transcription $\mathrm{CBP}$, and the transcription factors $\mathrm{CREB}$ and $\mathrm{NF}-\mathrm{KB}(60)$. Although GSK3- $\beta$ has been shown to regulate MyD88-dependent cytokine responses, whether GSK3- $\beta$ plays a functional role in the regulation of the prototypical MyD88-independent cytokine, IFN- $\beta$, is currently unknown.

In the present study, we show that GSK3- $\beta$ activity plays a fundamental role in regulating IFN- $\beta$ production. Specifically, we show that the phosphorylation of GSK3- $\beta$ (S9) in LPS-stimulated macrophages occurs in the absence of MyD88. Inhibition of GSK3- $\beta$ activity potently augmented the levels of IFN- $\beta$ in LPS-stimulated innate immune cells, whereas the ectopic expression of a constitutively active GSK3- $\beta$ mutant reduced IFN- $\beta$ production. Inhibition of GSK3- $\beta$ was found to control the cellular levels of the transcription factor c-Jun and this was demonstrated to be necessary for the ability of GSK 3 to control IFN- $\beta$ production. The functional role of GSK3- $\beta$ in regulating IFN- 
$\beta$ was confirmed in vivo in which the inhibition of GSK3- $\beta$ potently enhanced the systemic levels of IFN- $\beta$ in mice administered LPS. Taken together, these findings identify GSK $3-\beta$ as a critical regulatory kinase controlling IFN- $\beta$ production. 


\section{Materials and Methods}

\section{Mice and reagents}

C57BL/6 mice were purchased from The Jackson Laboratories. B6.MyD88 ${ }^{\%}$ mice were a gift from Shizuo Akira (via Ross Kedl, 3M Corporation) and were backcrossed $>6$ generations onto the C57BL/6 background. Mice were housed in a specific pathogenfree facility at the University of Louisville School of Medicine and the University of Louisville Institutional Animal Care and Use Committee approved all animal protocols. Ultra pure LPS from $E$. coli was purchased from Invivogen. All antibodies and recombinant cytokines were obtained from Cell Signaling Technology and R\&D Systems, respectively. The anti-HA antibody used for immunoblots was purchased from eBioscience. The GSK3-specific inhibitor SB216763 was previously characterized and was shown to be highly specific for GSK3 without discernible effects on a panel of 24 other kinases (114). SB216763 was purchased from Tocris. siRNAs were purchased from Dharmacon. The plasmid pcDNA3-GSK3ß(S9A) and pcDNA3-GSK3ß(K85A) were obtained from Addgene (plasmid numbers 14754 and 14755) and originally created by Dr. James Woodgett's laboratory (115). The nuclear levels of NF-kB p65 and IRF-3 were measured using the TransAM kit purchased from Active Motif. The amount of nuclear NF-B p65 or IRF-3 was normalized by the absorbance at $450 \mathrm{~nm}$ from $10 \mu \mathrm{g}$ (NF-B p65) or $20 \mu \mathrm{g}$ of nuclear lysate (IRF-3).

\section{Cell preparation}

Bone marrow derived macrophages (BM-DM) were prepared by culturing bone marrow 
from the femurs/tibiae of 6-10-wk-old mice in RPMI 1640 containing 5\% FBS, 2 mM Lglutamine, $1 \mathrm{mM}$ sodium pyruvate, $50 \mathrm{U} / \mathrm{ml}$ penicillin, $50 \mu \mathrm{g} / \mathrm{ml}$ streptomycin, $10 \mathrm{ng} / \mathrm{ml}$ M-CSF, and 30\% L929 conditioned medium. Non-adherent cells were collected after 24 $\mathrm{h}$ and cultured for 7 days in Costar ultra low attachment polystyrene culture dishes with a media change on day 4. BM-DM were $>85 \% \mathrm{CD} 1 \mathrm{~b}^{+}$, as demonstrated by flow cytometry.

\section{In vivo levels of IFN- $\beta$}

Male C57BL/6 mice (8-12 weeks of age; $20-28$ g body weight) were injected intraperitoneally with a $5 \mu \mathrm{g} / \mathrm{g}$ of LPS in $100 \mu \mathrm{l}$ of PBS containing $0.1 \%$ DMSO. Mice were analyzed for systemic levels of IFN- $\beta 6 \mathrm{~h}$ after being administered LPS in the presence of $0.1 \%$ DMSO or $10 \mu \mathrm{g} / \mathrm{g}$ of SB216763. The Institutional Animal Care and Use Committee of the University of Louisville approved all studies.

\section{Transfections and IFN- $\beta$ production}

BM-DM were transfected with non-targeting control (Ctrl) siRNA, siRNA-c-Jun, siRNAGSK3- $\beta$, pcDNA3-GSK3 $\beta($ S9A), pcDNA3-GSK3 $\beta(\mathrm{K} 85 \mathrm{~A})$ ), or pcDNA3 (empty vector control) using Lipofectamine RNAiMAX (Invitrogen), or Lipofectamine LTX (Invitrogen) following the manufacturer's protocol. The levels of total c-Jun and GSK3$\beta$ protein were assessed by Western blot on day 3. $2 \times 10^{5}$ BM-DM were cultured in 96well plates and pre-treated for $2 \mathrm{~h}$ with $0.01 \%$ DMSO (organic solvent control for SB216763) or the GSK3 inhibitor SB216763 (SB216763 at $12 \mu \mathrm{M}$ ) prior to LPS (1 $\mu \mathrm{g} / \mathrm{ml}$ ) stimulation. Transfected BM-DM were stimulated with LPS on day 3 post- 
transfection. Cell-free supernatants were assayed for IFN- $\beta$ levels by ELISA $20 \mathrm{~h}$ after the addition of LPS (R\&D Systems).

\section{RT-PCR, immunoprecipitation, immunoblots and statistical analysis}

Total RNA was isolated using the RNeasy Mini Kit (Qiagen) and real-time PCR was performed using an ABI 7500 system. GAPDH was used as the endogenous control and fold increase was calculated according to DDCT method. At the indicated time points, cells were harvested and analyzed by immunoblot or immunoprecipitation as previously described $(60,111)$. The Kodak 4000MM image system was used for obtaining all images and densitometer scans of the blots. The mouse True Blot kit (eBioscience) was used for all immunoprecipitations according to the manufacturer's protocol. A rabbit isotype control IgG antibody (Cell Signaling Technology) was used for all immunoprecipitations to ensure that the immunoprecipitation of ATF-2 and subsequent immunodetection of c-Jun were not due to non-specific interference. Data are expressed as mean $\pm \mathrm{SD}$ of a minimum of three experiments. Statistical significance between groups was evaluated by ANOVA and the Tukey multiple comparison test (Instat Program). Differences were considered significant at $P<0.05$. 


\section{$\underline{\text { Results }}$}

\section{TLR4-mediated phosphorylation of GSK3 $\beta$ (S9) occurs in the absence of MyD88}

LPS stimulation of innate immune cells has been shown to promote GSK3- $\beta$ inactivation via the phosphorylation of serine 9 (S9) $(58,60)$. To assess whether MyD88 is required for LPS to induce GSK3- $\beta$ (S9) phosphorylation, wild-type and MyD88deficient cells were compared in their abilities to phosphorylate GSK3- $\beta$ (S9) upon LPS stimulation (Fig. 1A). Both wild-type and MyD88-deficient macrophages demonstrated increased phospho-GSK $3 \beta$ (S9) levels after 30 and $60 \mathrm{~min}$ of culture in the presence of LPS, as compared to non-stimulated cells, (Fig. 1A). The phosphorylation of GSK3- $\beta$ (S9) in both wild type and MyD88-deficient cells was abrogated by the use of the PI3K inhibitors LY294002 or wortmannin (data not shown). A comparison of the ratios of phospho-GSK3- $\beta$ (S9) to that of total $\beta$-actin was similar between wild-type and MyD88-deficient cells (Fig. 1B, C). These results demonstrate that the phosphorylation of GSK3- $\beta$ (S9) in LPS-stimulated macrophages occurs in the absence of MyD88.

\section{GSK3 $\beta$ negatively regulates TLR4-induced IFN- $\beta$ production}

Since LPS induced the phosphorylation of GSK3- $\beta$ (S9) in the absence of MyD88

(Fig. 1), we next investigated whether GSK3 played a role in the production of the MyD88-independent cytokine, IFN- $\beta$. Pharmacological inactivation of GSK3 using the GSK3 inhibitor SB216763 (114) resulted in the loss of the GSK3-specific substrate phospho-glycogen synthase (Ser640/641), demonstrating the ability of SB216763 to 
inactivate endogenous GSK3 activity in macrophages (Fig. 2A). GSK3-inactivated macrophages stimulated with LPS produced significantly $(P<0.05)$ more IFN- $\beta$ protein and mRNA, as compared to cells stimulated with LPS alone (Fig. 2B, C). Moreover, LPS stimulation of macrophages treated with GSK3- $\beta$-specific siRNA $(>80 \%$ total GSK3- $\beta$ protein knockdown, (Fig. 3A) exhibited more than a 3-fold increase $(P<0.05)$ in secreted IFN- $\beta$ levels, as compared to cells treated with control siRNA and stimulated with LPS (Fig. 3B). TLR4-stimulation of macrophages expressing a kinase dead mutant of GSK3- $\beta$ (K85A) inhibited endogenous GSK3 activity (Fig. 3C, D) in macrophages and produced significantly $(P<0.05)$ elevated levels of IFN- $\beta$, as compared to empty vector transfected cells stimulated with LPS (Fig. 3E). In contrast, the ectopic expression of a constitutively active GSK3- $\beta$ (S9A) mutant severely attenuated the production of IFN- $\beta$ by LPS stimulated macrophages, as compared to empty vector transfected cells stimulated with LPS (Fig. 3E). Taken together, these results demonstrate that GSK3$\beta$ activity plays a fundamental role in controlling the production of IFN- $\beta$ by TLR4stimulated macrophages.

\section{GSK3 controls the nuclear levels of c-Jun/ATF-2 complexes by regulating total c-}

\section{Jun levels}

We next examined if serine/threonine phosphorylation by constitutively active GSK3 could be negatively affecting a downstream signaling molecule involved in the control of IFN- $\beta$ production. Previous studies have shown that c-Jun is a component of the IFN- $\beta$ enhanceosome (116) and that GSK3 can phosphorylate the transcription factor c-Jun on threonine 239 that, in turn, promotes c-Jun degradation $(117,118)$. We 
therefore tested whether GSK3 inhibition could affect the levels of phospho-c-Jun (Thr239) and total c-Jun in LPS-stimulated macrophages (Fig. 4A, B). Inactivation of GSK3 abrogated the ability of LPS stimulation to augment the levels of phospho-c-Jun (Thr239) in macrophages (Fig. 4A). Furthermore, the total levels of c-Jun were discernibly increased in GSK3-inactivated macrophages after 60 and especially $120 \mathrm{~min}$ of culture in the presence of LPS, as compared to non-stimulated or LPS-stimulated cells (Fig. 4B).

Since c-Jun has been shown to form a transcriptional complex with ATF-2 (116), we next examined whether GSK3-inhibition influenced the nuclear levels of c-Jun/ATF-2 complexes. Pull-down of nuclear ATF-2 and subsequent probing for associated c-Jun by Western blot demonstrated that GSK3 inhibition increased the total levels of c-Jun associated with ATF-2, as compared to the levels observed in cells stimulated with only LPS (Fig. 4D). Due to the transcriptional activity of c-Jun being regulated by phosphorylation on serines 63 and 73 (119), we also assessed the phosphorylation levels of these residues (Fig. 4C). Immunoprecipitation of nuclear ATF-2 and immunoblotting for associated levels of phospho-c-Jun (Ser63/Ser73) demonstrated that the levels of cJun (Ser63) and c-Jun (Ser73) were both highly elevated, as compared to macrophages stimulated with LPS alone (Fig. 4C). No discernible differences were observed in the levels of ATF-2 between groups (Fig. 4C, D). In contrast to the increased nuclear levels of c-Jun observed in GSK3-inhibited macrophages stimulated with LPS, no significant changes in the nuclear levels of NF-кB p65 or IRF-3 were observed (Fig. 5A, B). Therefore, active GSK3 negatively regulates the total cellular levels of c-Jun as well as the nuclear levels of c-Jun associated with ATF-2 in LPS-stimulated macrophages. 


\section{GSK3 inhibits TLR-4 induced IFN- $\beta$ production by regulating c-Jun levels}

To determine whether the increased c-Jun levels observed in GSK3 inhibited cells played a functional role in the ability of GSK3 to modulate IFN- $\beta$ levels by LPSstimulated macrophages, c-Jun levels were knocked down by transfecting macrophages with c-Jun-specific siRNA (Fig. 6A). Transfection with c-Jun-specific siRNA reduced cJun levels by over $90 \%$, as compared to non-transfected cells or cells transfected with control siRNA (Fig. 6A). The knockdown in c-Jun levels abrogated the ability of GSK3inhibition to significantly elevate the levels of IFN- $\beta$ produced by LPS-stimulated macrophages, as compared to control siRNA transfected cells stimulated with LPS (Fig. 6B). In contrast, GSK3-inhibited macrophages transfected with control siRNA and stimulated with LPS exhibited a significant $(P<0.05)$ increase in IFN- $\beta$ levels, as compared to cells treated with control siRNA and stimulated with LPS (Fig. 6B). Thus, the ability of GSK 3 to regulate the production of IFN- $\beta$ by LPS-stimulated macrophages is dependent upon GSK3's ability to modulate the cellular levels of c-Jun.

\section{GSK3 regulates the in vivo production of IFN- $\beta$}

We next wanted to determine if inhibiting GSK3 in vivo could modulate the induction of IFN- $\beta$ in mice given a sub-lethal dose of LPS. For this, mice were administered the GSK3 inhibitor SB216763 or DMSO $2 \mathrm{~h}$ before receiving LPS. The systemic levels of IFN- $\beta$ were monitored in mice $6 \mathrm{~h}$ after being given LPS (Fig. 7). Mice administered the GSK3 inhibitor SB216763 and challenged with LPS exhibited a significant increase in the levels of IFN- $\beta$, as compared to control mice that received 
DMSO and LPS (Fig. 7). No detectable levels of IFN- $\beta$ were observed in mice given DMSO or SB216763 alone (Fig. 5). These findings demonstrate targeting GSK3 in vivo potently increases the levels of IFN- $\beta$ upon LPS challenge. 


\section{Discussion}

The TLR4-signaling pathway in innate immune cells has been shown to mediate the induction of two distinct molecular pathways based on the usage of MyD88. The ability of TLR4 to recruit TIRAP-MyD88 and TRAM-TRIF to its cytosolic domain results in the production of pro-inflammatory cytokines and type I IFNs, respectively (31$33,109,110,120)$. Past studies by our group and others have demonstrated that the levels of MyD88-dependent cytokines, including both pro- and anti-inflammatory cytokines, were intimately controlled by GSK3- $\beta$. Specifically, the inactivation of GSK3- $\beta$ has been shown to negatively influence the levels of pro-inflammatory cytokines while concurrently augmenting the levels of the anti-inflammatory cytokine IL-10 in response to TLR4-stimulation $(60,112,113)$. The present study extends these previous findings by demonstrating that the inactivation of GSK3- $\beta$ (Ser9) occurs in the absence of MyD88 and GSK3- $\beta$ activity was a critical component of the regulatory mechanism that controlled the levels of IFN- $\beta$ by TLR4-stimulated cells both in vitro and in vivo. Thus, while the TLR4 signaling complex can mediate the production of both pro/antiinflammatory cytokines and IFN- $\beta$ via the recruitment of distinct adaptor molecules including TIRAP-MyD88 and TRAM-TRIF (31-33, 110, 120), respectively, the capacity of GSK3- $\beta$ to regulate both MyD88-dependent $(60,112,113)$ and MyD88-independent cytokine responses highlights the central importance that GSK3- $\beta$ plays in the regulation of the host innate inflammatory response.

The identification and characterization of the downstream cell-signaling events regulating the IFN- $\beta$ response have been shown to involve the activation of the kinases 
TBK-1 and IKK- $\varepsilon$ that are involved in the phosphorylation of the transcription factor IRF-3 and its subsequent dimerization and translocation into the nucleus (35) (121) (122). The critical importance of TBK-1 and IKK- $\varepsilon$ in regulating IFN- $\beta$ via IRF-3 are highlighted by the findings that cells deficient in IRF-3 are unable to produce IFN$\beta$ (123). In addition to IRF-3, studies analyzing the inf $\beta$ promoter have revealed the presence of additional regulatory molecules that can bind one of the four positive regulatory domains within the ifn $\beta$ promoter. In this regard, ATF- 2 and c-Jun have been shown to bind the ifn $\beta$ promoter via a heterodimeric complex within the positive regulatory domain IV of the ifn $\beta$ promoter (116) (86) (91). Although the findings of the present study did not observe any discernible effects of GSK3 inhibition on the activity of IRF-3, the ability of GSK3 to regulate the cellular levels of c-Jun were found to be of critical importance for the ability of GSK3 to modulate IFN- $\beta$ production by LPSstimulated innate immune cells. Moreover, siRNA-mediated knockdown of c-Jun levels in macrophages reduced the levels of IFN- $\beta$ produced by cells stimulated with LPS. These findings demonstrate a fundamental role for c-Jun in the regulation of IFN- $\beta$ and highlight the underlying molecular mechanism by which GSK3 regulates IFN- $\beta$ by LPS stimulated innate immune cells.

The ability of GSK3 activity to differentially regulate the levels of MyD88dependent pro/anti-inflammatory cytokines while concurrently controlling the production of the MyD88-independent cytokine, IFN- $\beta$, demonstrated the existence of a crosstalk network between these two pathways mediated by GSK3. Interestingly, the downstream molecular mechanism by which GSK3- $\beta$ regulated MyD88-dependent and MyD88indpendent cytokine responses are unique. Studies by our laboratory were the first to 
show active GSK3- $\beta$ negatively regulated the levels of the anti-inflammatory cytokine IL-10 while simultaneously promoting the production of pro-inflammatory cytokines by TLR-stimulated innate immune cells (60). Analysis of the mechanism by which GSK3- $\beta$ influenced the transcriptional control of MyD88-dependent cytokines revealed GSK3 repressed the nuclear association of the transcription factor CREB (Ser133) with the coactivator of transcription CBP. Upon GSK3 inactivation, IL-10 production increased while pro-inflammatory cytokine production was severely suppressed due to the displacement of NF-KB p65 from CBP by CREB (60). Although the inhibition of GSK3 did exhibit similar effects on the nuclear levels of CREB as has been previously reported (60), knockdown in the levels of CREB within the context of the current study did not affect the ability of GSK3 inhibition to modulate IFN- $\beta$ production by LPS-stimulated innate immune cells (H. Wang and M. Martin, unpublished observations). However, GSK3 was found to also control c-Jun levels that resulted in increased nuclear levels of ATF-2/c-Jun complexes. siRNA-mediated gene silencing of c-Jun demonstrated that the ability of GSK3 to regulate IFN- $\beta$ production by TLR4-stimulated macrophages was dependent upon increased c-Jun levels. Thus, the ability of GSK3- $\beta$ to regulate both MyD88-dependent and MyD88-independent cytokine responses occur via different molecular mechanisms.

In conclusion, we have demonstrated that the constitutively active kinase, GSK3, plays a fundamental role in controlling the production of IFN- $\beta$. Our results showed that the production of IFN- $\beta$ by LPS-stimulated macrophages was regulated by the activity of GSK3- $\beta$ and its ability to affect the cellular and subsequent nuclear levels of the transcription factor c-Jun associated with ATF-2. Overall, the current findings identify 
GSK3 as a fundamental kinase involved in the regulation of the MyD88-independent cytokine, IFN- $\beta$, and provide a rationale to modulate the levels of IFN- $\beta$ in vivo. 


\section{Figure 1}

A
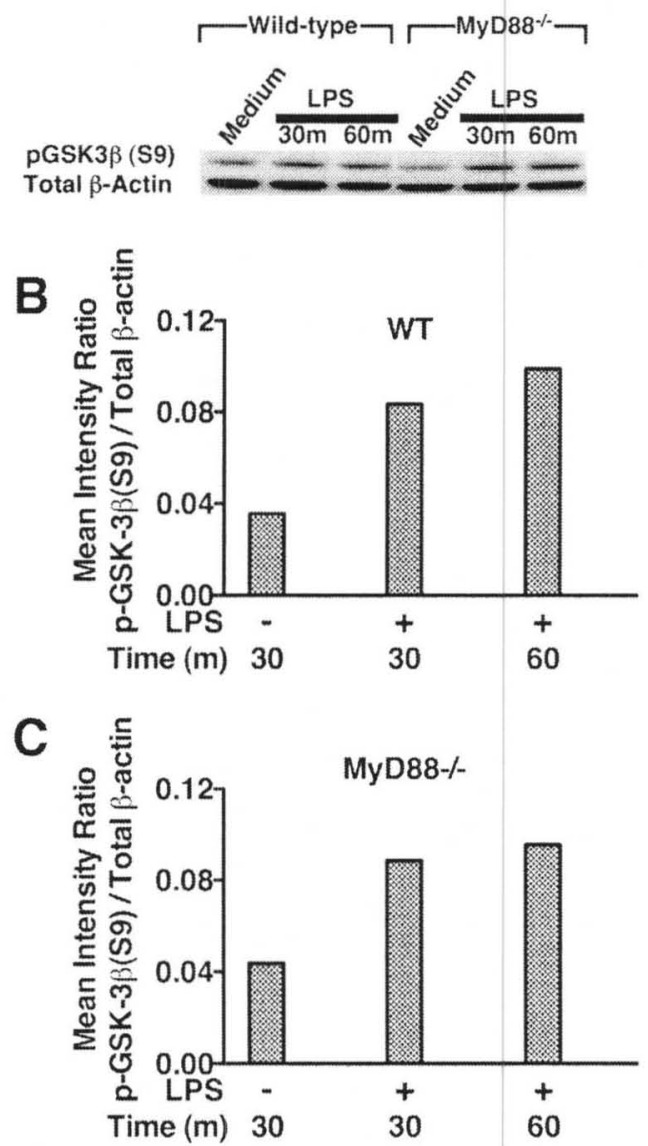

Figure 1. Stimulation of macrophages with LPS induces the phosphorylation of GSK3- $\beta$ (S9) in both wild-type and MyD88-deficient macrophages. (A) Wild-type and MyD88-deficient macrophages were stimulated with $1 \mu \mathrm{g} / \mathrm{ml}$ of LPS for 30 or 60 min. To assess phospho-GSK3- $\beta$ (S9), $15 \mu \mathrm{g}$ of total cell lysate was resolved on LDSPAGE, immunoblotted with an anti-phospho GSK3- $\beta$ (S9) Ab, and developed by ECL. Immunoblots were stripped and reprobed with an $\mathrm{Ab}$ to total $\beta$-actin to ensure equal protein loading. (B, C) Densitometer scans of phospho-GSK3- $\beta$ (S9) and total $\beta$-actin were performed and recorded as the ratio of phospho-GSK3- $\beta$ (S9):total $\beta$-actin. Data are representative of 3 separate experiments. 


\section{Figure 2}

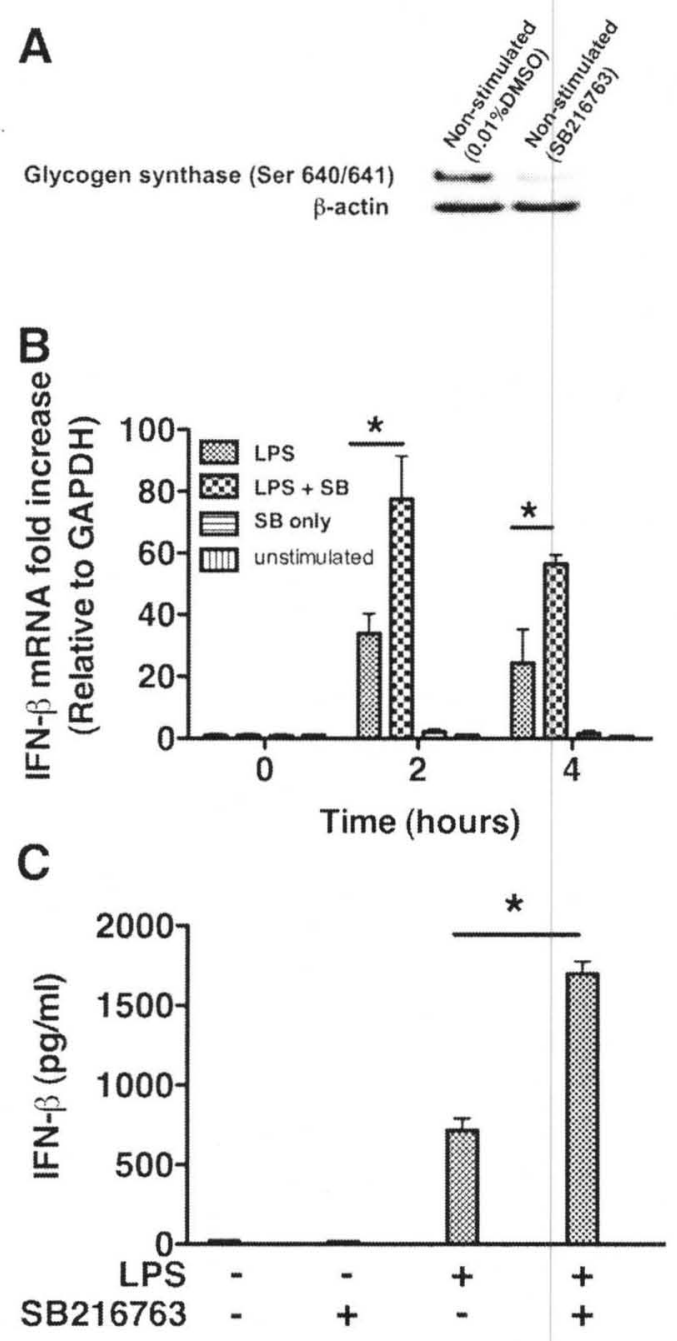

Figure 2. GSK3 negatively controls IFN- $\beta$ production by LPS-stimulated

macrophages. (A) Macrophages treated with the GSK3 inhibitor SB216763 exhibited a loss in the phosphorylation levels of the GSK3-specific substrate glycogen synthase (Ser640/641). Macrophages were pre-treated with GSK3 inhibitor SB216763 for $2 \mathrm{~h}$ and then stimulated with $1 \mu \mathrm{g} / \mathrm{ml}$ LPS. Inhibition of GSK3 augmented the (B) mRNA and (C) protein levels of IFN- $\beta$ produced by TLR4-stimulated macrophages. ${ }^{*}$ indicates statistically significant differences at $P<0.05$ between the indicated groups. Results represent the mean $\pm \mathrm{SD}$ of three separate experiments. 


\section{Figure 3}

A
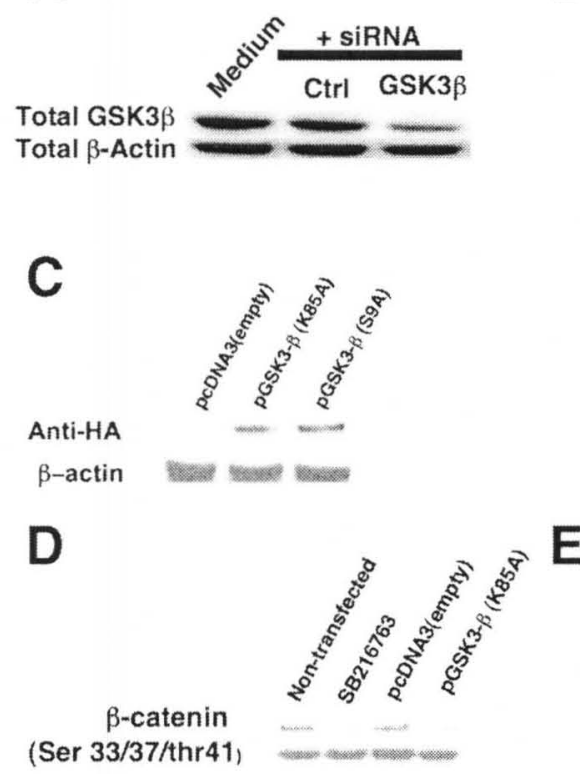
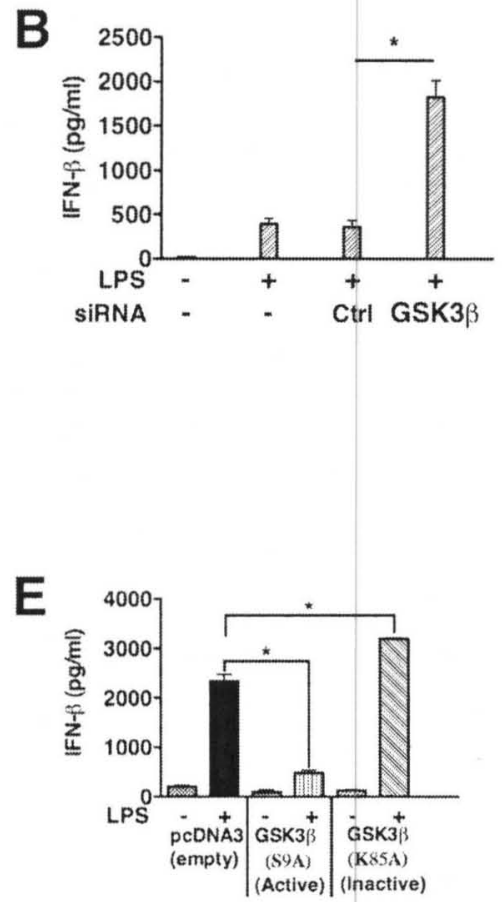

Figure 3. LPS induced IFN $\beta$ production is dependent on GSK3 $\beta$, activity. siRNAmediated knockdown of (A) GSK3- $\beta$ protein levels increased the production of (B) IFN$\beta$ by LPS-stimulated ( $1 \mu \mathrm{g} / \mathrm{ml})$ macrophages. (C) HA expression levels in nontransfected macrophages or macrophages transfected with a kinase dead (K85A) or constitutively active (S9A) plasmid encoding GSK3- $\beta$. Levels of HA were detected by Western blot $48 \mathrm{~h}$ after transfection. (D) Expression of the kinase dead (K85A) GSK3 mutant in macrophages inhibited the endogenous phosphorylation of the GSK3-specific substrate $\beta$-catenin (Ser33/37/Thr41). (E) As compared to empty vector control macrophages stimulated with LPS $(1 \mu \mathrm{g} / \mathrm{ml})$, the constitutively active GSK3- $\beta$ (S9A) and kinase dead GSK3- $\beta$ (K85A) negatively and positively, respectively, regulated IFN- $\beta$ production by macrophages stimulated with LPS $(1 \mu \mathrm{g} / \mathrm{ml}) .{ }^{*}$ indicates statistically significant differences at $P<0.05$ between the indicated groups. Results represent the mean $\pm \mathrm{SD}$ of three separate experiments. 


\section{Figure 4}
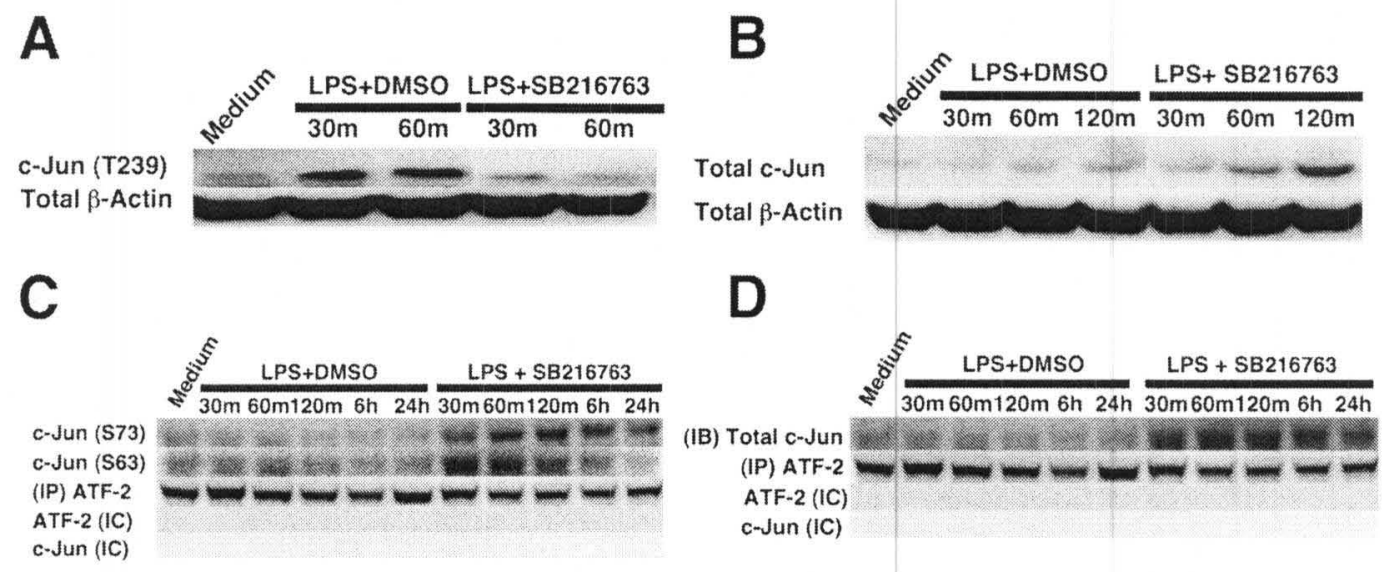

Figure 4. GSK3 negatively affects the levels of nuclear c-Jun/ATF-2 heterodimer complexes by controlling total c-Jun levels. Inhibition of GSK3 attenuates the levels of (A) phospho-c-Jun (Thr239) and increases (B) total c-Jun levels in LPS-stimulated macrophages. GSK3 inhibition increases the association of (D) total and (C) phospho-cJun (Ser63/73) to ATF-2 in LPS-stimulated macrophages. For A and B, cell lysates were prepared at the given time points, and $15 \mu \mathrm{g}$ of total protein was analyzed by immunoblot using Abs to c-Jun (Thr239) or total c-Jun, stripped, and reprobed with an Ab to total $\beta$ actin to ensure equal protein loading. (C, D) Nuclear lysates were prepared the given time points, a rabbit isotype control (IC) IgG or total ATF-2 was immunoprecipitated, and associated (C) total and (D) phospho-c-Jun (Ser63/73) were determined by immunoblot. (C, D) Total ATF-2 was monitored by immunoblot between groups to ensure equivalent pull-down of ATF-2. (C, D) No immunoreactive bands were detected at 43 or $48 \mathrm{kDa}$ (c-Jun) or $65-75 \mathrm{kDa}(\mathrm{ATF}-2)$ when a rabbit isotype control (IC) antibody was used for immunoprecipitation. Data are representative of 3 separate experiments. 
Figure 5

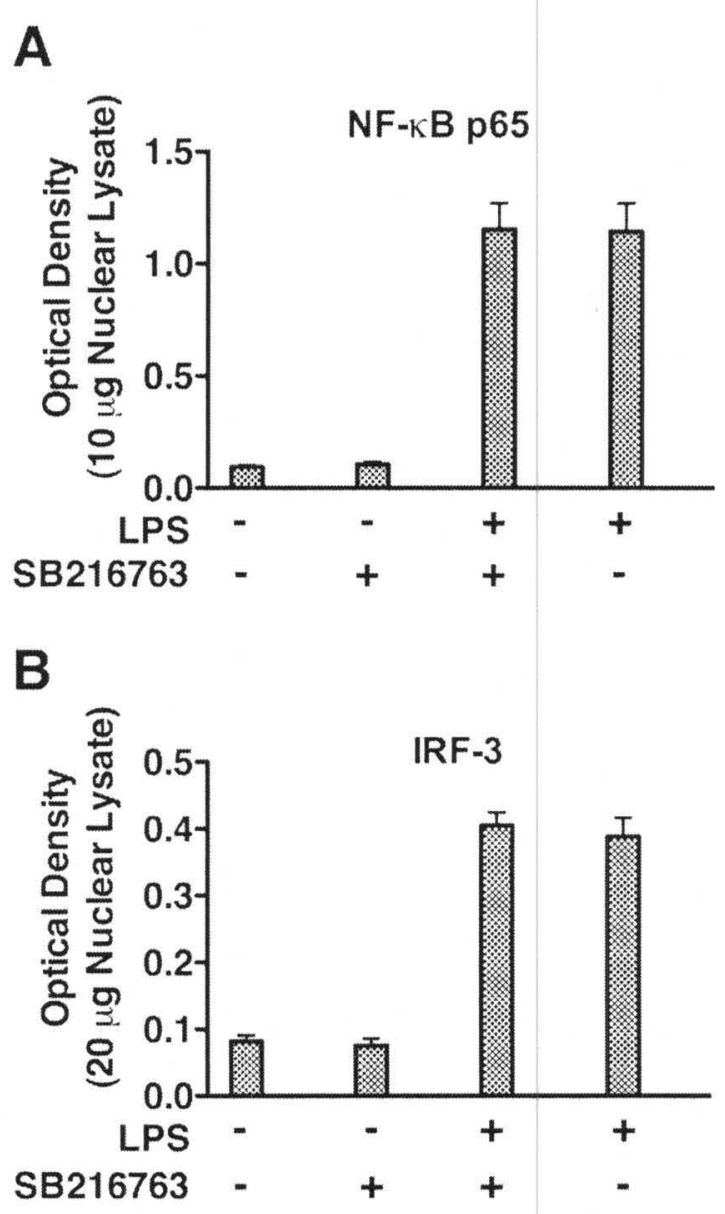

Figure 5. GSK3 has no discernible effect on the nuclear levels of the transcription factors NF-K B and IRF-3. In contrast to the effect of GSK3 inhibition of c-Jun, GSK3 inhibition did not discernibly affect the nuclear levels of the transcription factors (A) NF$\kappa \mathrm{B}$ or (B) IRF-3. The transcription factor binding levels of (A) NF- $\kappa \mathrm{B}$ p65 using $10 \mu \mathrm{g}$ of nuclear lysate or (B) IRF-3 using $20 \mu \mathrm{g}$ of nuclear lysate were obtained from macrophages stimulated with LPS for $6 \mathrm{~h}$. Data represent the mean $\pm \mathrm{SD}$ of three separate experiments. 


\section{Figure 6}

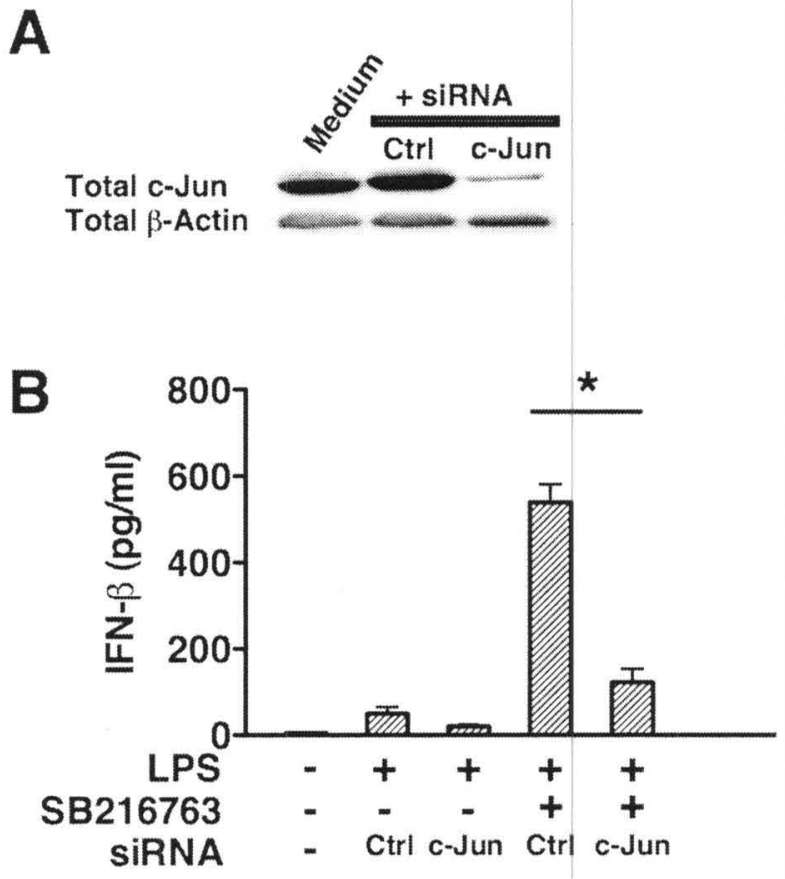

Figure 6. GSK3 controls IFN- $\beta$ production by regulating c-Jun levels in LPSstimulated macrophages. (A, B) The siRNA-mediated knockdown in c-Jun protein levels abrogates the ability of GSK3 inhibition to augment IFN- $\beta$ production by LPSstimulated macrophages $(1 \mu \mathrm{g} / \mathrm{ml})$. For A, total c-Jun levels were determined $72 \mathrm{~h}$ posttransfection by immunoblot. For B, cell-free supernatants were harvested $20 \mathrm{~h}$ after LPS stimulation $(1 \mu \mathrm{g} / \mathrm{ml})$ and analyzed for IFN- $\beta$ levels by ELISA. ${ }^{*}$ indicates statistically significant differences at $P<0.05$ between the indicated groups. Results represent the mean $\pm \mathrm{SD}$ of three separate experiments. 


\section{Figure 7}

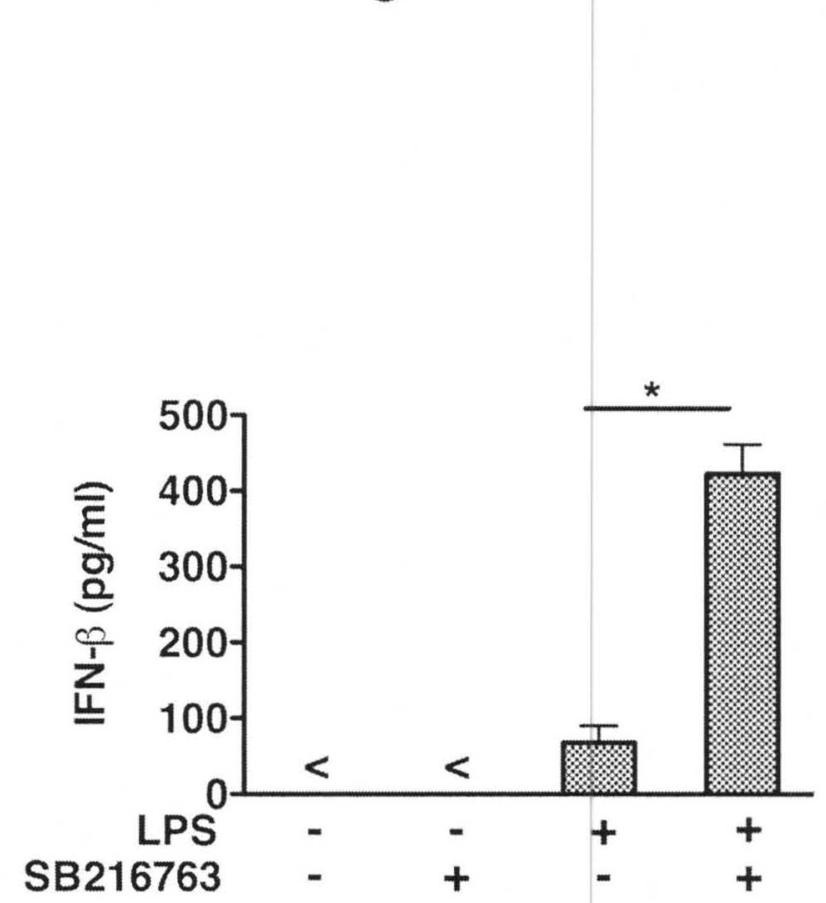

Figure 7. Inhibition of GSK3 augments the systemic levels of IFN- $\beta$ by mice given LPS. Intraperitoneal administration of the GSK3 inhibitor SB216763 (10 $\mu \mathrm{g} / \mathrm{g})$ significantly increased the levels of IFN- $\beta$ by mice given $5 \mu \mathrm{g} / \mathrm{g}$ of LPS. Results represent the mean $\pm \mathrm{SD}$ of five mice/group. In vivo levels of IFN- $\beta$ in plasma were measured by ELISA $6 \mathrm{~h}$ after mice were given LPS. Sham-immunized mice were given PBS containing $0.1 \%$ DMSO. ${ }^{*}$ indicates statistically significant differences at $P<0.05$ compared with control mice given LPS containing 0.1\% DMSO. All groups of mice were given PBS containing 0.1\% DMSO with or without LPS or SB216763. 
MODEL FOR THE ROLE OF GSK3 IN REGULATING THE PRODUCTION OF IFN-BETA BY TLR4 STIMULATED INNATE IMMUNE CELLS

\section{TLR4/PI3K Pathway}

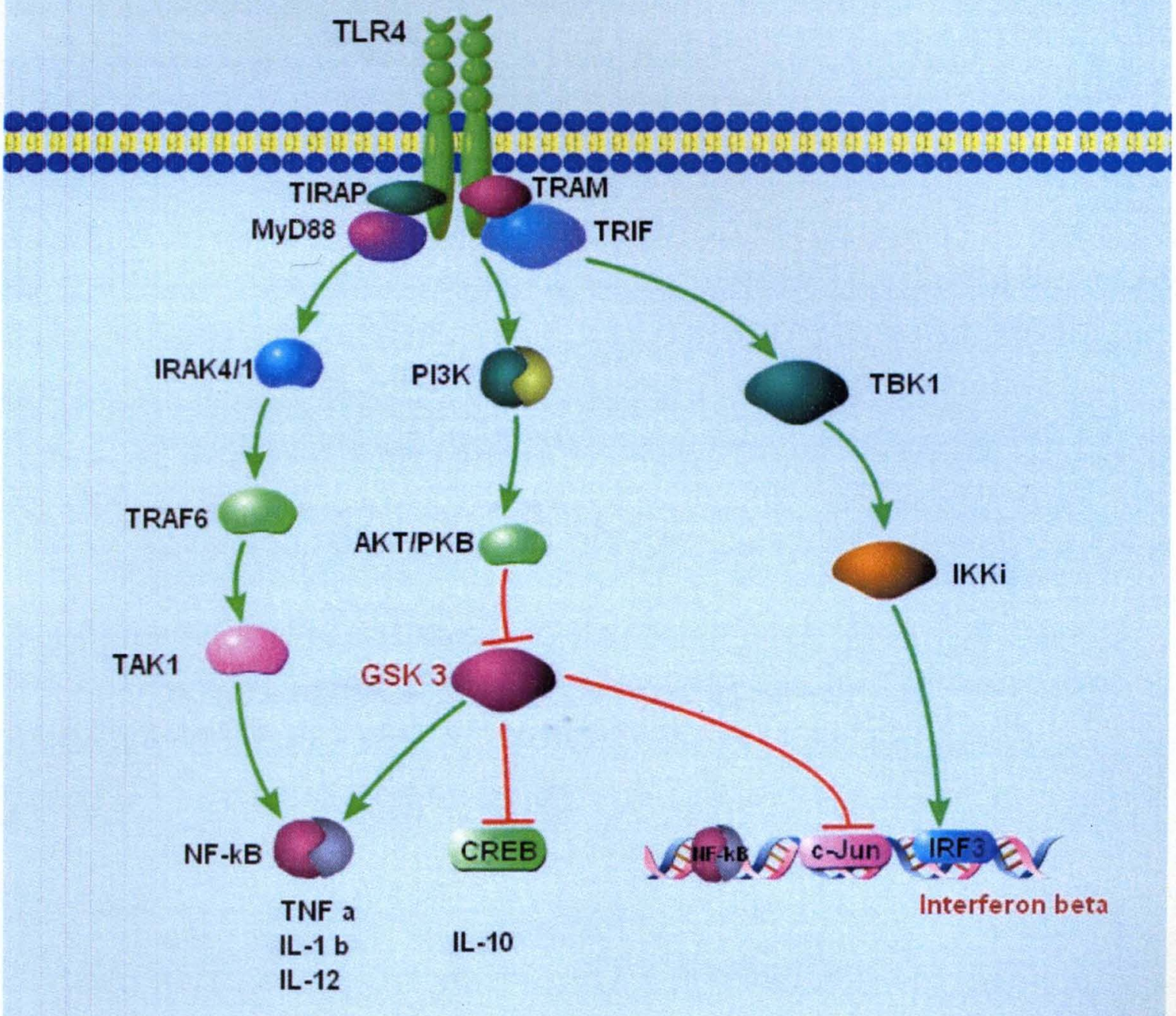




\section{CHAPTER III}

\section{INTERFERON-BETA INDUCES IL-10 PRODUCTION BY REGULATING GLYCOGEN SYNTHASE KINASE-3 BETA}

\section{Introduction}

Interferon- $\beta$ (IFN- $\beta$ ) is a member of the type I IFN cytokine family (61). Although originally identified as playing a critical role in anti-viral immunity, type I IFNs are now recognized as important immunomodulators that play a crucial role in both the innate and adaptive immune systems $(94,95,124)$. In this regard, past studies have highlighted the importance of type I IFNs in mediating the production of the anti-inflammatory cytokine IL-10 by innate immune cells $(99,100)$. Previous studies by Chang et al (101) have demonstrated a fundamental role for IFN- $\beta$ in regulating the levels of IL-10 produced by Toll-like receptor (TLR)-stimulated innate immune cells. Several other studies have additionally shown that IFN- $\beta$ can modulate the immune response to other cellular stimuli by positively controlling the production of IL-10 (102-104). Due to their immunomodulatory properties, type I IFNs have also been extensively for the initial treatment of relapsing remitting multiple sclerosis (MS) (65-67). Although the precise therapeutic mechanism of action of IFN- $\beta$ in MS treatment is unclear, IFN- $\beta$ treatment has been shown to increase the serum levels of IL-10 present in MS patients (100), and this effect is believed to play a role in the therapeutic value of type I IFNs in the 
treatment of MS patients (105). Despite the numerous reports linking IFN- $\beta$ to the induction of IL-10 production, the underlying cellular mechanisms responsible for the ability of IFN- $\beta$ to induce IL-10 production remains unresolved.

Previous studies have shown that type I IFNs can engage several signaling pathways including the Janus kinase-signal transducers and activators of transcription (JAKSTAT), p38 mitogen-activated protein kinase (MAPK), and phosphoinositide 3-kinase (PI3K) pathways $(97,125,126)$. The ability of type I IFNs to activate multiple signaling cascades is likely responsible for their pleiotropic biological effects on the immune system. Past studies by several groups have demonstrated that type I IFNs can induce the activation of the PI3K pathway and mediate the phosphorylation of several downstream kinases within this pathway, including AKT, mTOR, and p70S6K (51-53). Although previous studies have demonstrated a central role of the PI3K pathway in the regulation of IL-10 by Toll-like receptor (TLR) stimulated innate immune cells $(111,127)$, the functional role this pathway plays in the ability of type I IFNs to promote IL-10 production by innate immune cells has not been previously investigated.

Glycogen synthase kinase 3 (GSK3) is a constitutively active serine/threonine kinase that is downstream of the PI3K/AKT pathway, and exists as two major isoforms, GSK3$\alpha$ and GSK3- $\beta$ (50). GSK3 has been recognized as a key regulator in a diverse number of biological processes, including the regulation of the host inflammatory response $(60,128$, 129). Specifically, past studies by our laboratory and others have demonstrated the pivotal role GSK3- $\beta$, plays in controlling IL-10 production by TLR-stimulated cells. Given the importance of GSK3 in regulating IL-10 production $(60,113,130)$, and the ability of type I IFNs to activate the PI3K pathway $(131,132)$, we investigated whether 
type I IFNs regulated the activity of GSK3 and if this process played a functional role in their ability to induce IL-10. 


\section{Materials and Methods}

\section{Media and Reagents.}

Cells were cultured in RPMI 1640 medium supplemented with $10 \%$ FBS, $50 \mu \mathrm{M}$ 2-mercaptoethanol, $1 \mathrm{mM}$ sodium pyruvate, $2 \mathrm{mM} \mathrm{L-glutamine,} 20 \mathrm{mM}$ HEPES, $50 \mathrm{U} / \mathrm{ml}$ penicillin, and $50 \mu \mathrm{g} / \mathrm{ml}$ streptomycin. Ultra pure LPS from E. coli 0111:B4 was purchased from Invivogen. Neutralizing anti-IFN- $\beta$ antibody was purchased from R\&D Systems. All other antibodies and recombinant human IFN- $\beta$ were obtained from Cell Signaling Technology and R\&D Systems, respectively. Recombinant human interleukin4 (rhIL-4) and recombinant granulocyte macrophage-colony stimulating factor (rhGMCSF) were purchased from R\&D Systems. The GSK3 inhibitor SB216763 was previously characterized and was shown to be specific for GSK3 without discernible effects on a panel of 24 other kinases (114). SB216763 and wortmannin (PI3K inhibitor) were purchased from Tocris and LC Laboratories, respectively. Non-targeting pools of siRNA and a mixture of four pre-validated siRNA duplexes specific for GSK3-b (ON TARGET-plus ${ }^{\mathrm{TM}}$ ) were purchased from Dharmacon. TaqMan probes were purchased from Applied Biosystems. The plasmid pcDNA3-GSK3-b(S9A) and pcDNA3-GSK3$b(K 85 A)$ were obtained from Addgene (plasmid numbers 14754 and 14755) and originally created by Dr. James Woodgett's laboratory (115). Lipofectamine RNAiMAX and Lipofectamine LTX were obtained from Invitrogen.

\section{Human monocyte derived dendritic cells.}

Peripheral blood mononuclear cells (PBMCs) were obtained from healthy donors 
as per protocols approved by the University of Louisville, Institutional Review Board, Human Subjects Protection Program, study number 503.05. Monocytes were isolated by negative selection using the human monocyte isolation kit II from Miltenyi Biotec Incorporated. The purity of monocytes was routinely $>90 \%$, as determined by flow cytometry using a FITC-labeled anti-CD14 antibody. Purified monocytes were cultured in 6-well tissue culture plates at $2 \times 10^{6} / \mathrm{ml}$ in culture medium supplemented with 50 $\mathrm{ng} / \mathrm{ml}$ of rhGM-CSF and $100 \mathrm{ng} / \mathrm{ml}$ of rhIL-4. The medium was replaced on day 4 . On day 9, cells were harvested, washed 2 times with DPBS, and rested overnight before being used in experiments. On day 9 , the levels of CD1a were typically greater than $80 \%$, as determined by flow cytometry.

\section{Cell transfection, Western blot, and IL-10 production.}

DCs were transfected with non-targeting control (Ctrl) siRNA, siRNA-GSK3-b, pcDNA3-GSK-3b(S9A), pcDNA3-GSK3-b(K85A), or pcDNA3 (empty vector control) using Lipofectamine RNAiMAX or Lipofectamine LTX following the manufacturer's protocol (Invitrogen). Cell lysates were prepared as previously described (111) (60). Twenty micrograms of total cellular protein from each group was suspended in lithium dodecyl sulfate (LDS) buffer, heated for $10 \mathrm{~min}$ at $70^{\circ} \mathrm{C}$, resolved by LDS-PAGE, and then transferred to polyvinylidene difluoride membranes using the Novex system (Invitrogen). Probing and visualization of immunoreactive bands were performed using the ECL Plus kit (Amersham Pharmacia) by following the manufacturer's protocol. Images were acquired using the Kodak Image Station 4000MM system (Eastman Kodak, New Haven, CT). For siRNA studies, the levels of total GSK3-b and b-actin were 
assessed by Western blot on day 3. Cells were pre-treated for $2 \mathrm{~h}$ with $0.01 \%$ DMSO (organic solvent control for SB216763 or wortmannin) or the GSK3 inhibitor SB216763 $(10 \mathrm{mM})$ or wortmannin $(250 \mathrm{nM})$ prior to IFN- $\beta(1000 \mathrm{U} / \mathrm{ml})$ stimulation. Transfected DC were stimulated with IFN- $\beta$ on day 3 post-transfection and cell-free supernatants were assayed for IL-10 levels by ELISA $20 \mathrm{~h}$ after the addition of IFN- $\beta$ (R\&D Systems).

\section{RT-PCR and Western Blot analysis.}

RNA extraction and first strand cDNA synthesis was performed using the 5 Prime PerfectPure RNA Cultured Cell Kit and High-Capacity cDNA Archive kit (Applied Biosystems). Real-time PCR was performed using an ABI 7500 system. GAPDH mRNA levels were determined for each time point and used as the endogenous control. Fold increase was calculated according to DDCT method (133).

\section{Flow Cytometric Analysis}

Cells were plated at $2.5 \times 10^{5}$ cells/well in a $96-$ well flat bottom plate. Cells were pre-treated with the indicated pharmacological inhibitor, siRNA, or anti- IFN- $\beta$ antibody. For the detection of intracellular phospho-GSK3- $\beta$, cells were harvested at the given time points, transferred to $5 \mathrm{ml}$ polystyrene round-bottom tubes, washed twice with $2 \mathrm{ml}$ of FACS buffer (PBS containing 2\% FBS and $0.01 \%$ sodium azide), and then fixed by adding $500 \mathrm{ml}$ of formaldehyde to a final concentration of $4 \%$ in PBS for $10 \mathrm{~min}$ at room temperature. Cells were washed once in PBS and re-suspended in $500 \mathrm{ml}$ of $90 \%$ methanol and incubated on ice for 10 min. Cells were then washed in PBS containing $2 \% \mathrm{FBS}$, and then re-suspended in PBS containing 2\% FBS containing an anti-phospho- 
GSK3- $\beta$ antibody (Cell signaling) or isotype control antibody. Cells were incubated at room temperature for 30 minutes, washed twice in PBS containing 2\% FBS, and analyzed immediately by flow cytometry. For the detection of intracellular IL-10 levels, the levels of IL-10 were assessed by adding monensin during the last $6 \mathrm{~h}$ of a $20 \mathrm{~h}$ stimulation. Cells were fixed in $4 \%$ paraformaldehdye, permeabilized using eBioscience Perm buffer, and incubated with anti-human IL-10-FITC antibody for 30 minutes. Samples were then washed twice with Perm buffer and analyzed immediately by flow cytometry.

\section{Statistical analysis}

Statistical significance between groups was evaluated by the analysis of variance and the Tukey multiple comparison test using the InStat program (GraphPad, San Diego, Calif.). Differences between groups were considered significant at the level of $P$ values $<$ 0.05 . 


\section{$\underline{\text { Results }}$}

\section{LPS-mediated IFN- $\beta$ enhances IL-10 production from DCs}

Chang et al. (101) recently reported that IFN- $\beta$ played an important role in the ability of LPS-stimulated mouse bone marrow derived macrophages to produce IL-10. In order to determine whether IFN- $\beta$ mediated a similar role in human DCs, cells were pretreated with anti-interferon $\beta$ or isotype control antibody for $2 \mathrm{~h}$ and then stimulated with LPS (Fig. 8A). DCs stimulated with LPS in the presence of an anti-IFN- $\beta$ antibody exhibited a significant $(* * *, \mathrm{P}<0.001)$ decrease in the levels of IL-10, as compared to cells stimulated with LPS in the presence of an isotype control antibody (Fig. 8A). Moreover, as determined by flow cytometry, cells stimulated with LPS exhibited greater than a two-fold increase in the levels of IL-10, as compared to DC stimulated with LPS in the presence of an anti-IFN- $\beta$ antibody (Fig. 8B). Since these studies demonstrated that IFN- $\beta$ played an important role in LPS-mediated IL-10 production, we next assessed if IFN- $\beta$ alone was capable of inducing IL-10 from human DC. As compared with untreated cells, the addition of IFN- $\beta$ significantly $(\mathrm{P}<0.05)$ enhanced the production of IL-10 at all concentrations tested, whereas no effect was observed with respect to the levels of the pro-inflammatory cytokines, TNF $\alpha$, IL-1b, IL-12 p40, or IL-23 (Fig. 9A-D). These results demonstrate that IFN- $\beta$ produced by LPS-stimulated cells, or in isolation, plays an important role in the ability of DC to produce IL-10.

\section{IFN- $\beta$ activates the PI3K pathway and mediates the subsequent inactivation of GSK3-B}


Previous studies have reported that type I IFNs can engage the PI3K pathway and activate downstream effector kinases, such as AKT, mTOR, and p70S6K (52) (53). Since the induction of IL-10 from innate immune cells upon TLR stimulation is critically dependent on the ability of PI3K pathway to mediate the phosphorylation dependentinactivation of GSK3 $\beta$, we next investigated whether GSK $\tilde{3}$ b is inactivated upon IFN- $\beta$ stimulation of human DCs and if this process was dependent on the activity of PI3K. For this, DCs were stimulated with IFN- $\beta$ in the presence or absence of a PI3K inhibitor (LY294002) and the levels of phospho-Akt (Thr 308 and Ser473) and phospho-GSK3- $\beta$ (Ser9) were assessed by Western blot and flow cytometry. Optimal physiological activation or repression of Akt and GSK3 activity, respectively, is dependent on the phosphorylation of the sites Thr308 and Ser473 on Akt and Ser9 on GSK3- $\beta(60)$. As shown in figure 10 , IFN- $\beta$ stimulated DCs exhibited increased levels of both phosphoAkt (Thr308 and Ser473) and phospho-GSK3-bß (Ser 9), as compared to non-stimulated cells. Furthermore, inhibition of PI3K activity abrogated the ability of IFN- $\beta$ to induce the phosphorylation of both Akt and GSK3- $\beta$. (Fig.10A-B). We further examined the levels of phospho-GSK3- $\beta$ in IFN- $\beta$-stimulated DCs at the single cell level by flow cytometry. As shown in figure 11 , IFN- $\beta$ stimulation increased the percent of DCs expressing phospho-GSK3- $\beta$ from $0.63 \%$ in the non-stimulated control cells to over $31.3 \%$ in IFN- $\beta$ stimulated cells. Moreover inhibition of PI3K activity attenuated the increased levels of phospho-GSK3-b observed in IFN- $\beta$ stimulated DCs. Thus, IFN- $\beta$ mediates the PI3K-dependent phospho-inactivation of GSK3- $\beta$ in human dendritic cells.

\section{Suppression of GSK3- $\beta$ activity is critical for IFN- $\beta$-induces IL-10 production}


Given the importance of GSK 3 in regulating IL-10 production $(60,113,130)$, and the ability of IFN- $\beta$ to induce phospho-inactivation of GSK $3-\beta$ in a PI3K dependent manner (Fig. 10B), we next investigated whether this process played a functional role in the ability of IFN- $\beta$ to induce IL-10 from human DCs. To initially test this possibility, DCs were stimulated with IFN- $\beta$ in the presence or absence of a PI3K inhibitor, and the production of IL-10 was monitored by ELISA and flow cytometry. As shown in figures $12 \mathrm{~A}$ and $\mathrm{B}$, inhibition of PI3K significantly $(\mathrm{P}<0.01)$ decreased the levels of $I L-10$ produced by IFN- $\beta$ stimulated DC. To directly assess whether GSK3 plays a functional role in the ability of IFN- $\beta$ to induce IL-10, we next pre-treated human DCs with the GSK3 inhibitor SB216763 and subsequently stimulated with IFN- $\beta$. Inhibition of GSK3 significantly $(P<0.01)$ enhanced both the steady state levels of IL-10 mRNA and the amount of IL-10 protein produced upon IFN- $\beta$ stimulation of DCs, as compared to cells treated with IFN- $\beta$ alone (Fig. 12C, D).

We next used siRNA-mediated gene silencing to confirm the functional role of the GSK3- $\beta$ isoform in suppressing IL-10 production from IFN- $\beta$ treated cells. Human DCs exhibiting a knockdown in the cellular levels of GSK3- $\beta$ protein produced significantly $(\mathrm{P}<0.05)$ elevated levels of IL-10 upon stimulation with IFN- $\beta$. (Fig. 13B), as compared to cells transfected with non-targeting siRNA and stimulated with IFN- $\beta$. In addition, IFN- $\beta$-stimulation of DC expressing a kinase dead mutant of GSK3- $\beta$ (K85A) inhibited endogenous basal GSK3 activity (data not shown) and produced significantly $(\mathrm{P}<0.05)$ elevated levels of IL-10, as compared with empty vector transfected cells stimulated with IFN- $\beta$. (Fig. 13C). In contrast, the ectopic expression of a constitutively active GSK3- $\beta$ (S9A) mutant severely attenuated the ability of IFN- $\beta$ to stimulate human 
DC to produce IL-10, as compared with empty vector transfected cells stimulated by IFN- $\beta$ (Fig. 13C). Taken together, these results demonstrate that the repression of GSK3bactivity in human DCs observed upon IFN- $\beta$-stimulation is a fundamental process involved in the regulation of IFN- $\beta$ induced IL-10 production.

\section{IF $N$ - $\beta$ induces partial but not complete inactivation of GSK3-b activity}

The data from the current study demonstrates that IFÑ increased the phosphorylation of GSK3- $\beta$ (Ser9) and preventing this phospho-inactivation of GSK3-b abrogated the ability of IFN- $\beta$ to induce IL-10 by human DCs. Moreover, our findings obtained from both pharmacological inhibition and siRNA-mediated knockdown of GSK3 demonstrated that a further reduction in GSK3- activity enhanced the levels of IL10 by IFN- $\beta$-stimulated cells, as compared to cells stimulated with IFN- $\beta$ alone. Thus, as compared to cells stimulated with IFN- $\beta$ alone, the findings that either pharmacological inhibition or siRNA-mediated knockdown of GSK3 significantly $(\mathrm{P}<0.01)$ increased the levels of IL-10 produced by IFN- $\beta$ stimulated cells, suggest that the differences in IL-10 levels are due to differences in their ability to inactivate GSK3- $\beta$. To test this possibility, we monitored the relative level of GSK 3 activity by assessing the phospho-levels of the GSK3-specific substrate, glycogen Synthase (GS) $(134,135)$. As compared to nonstimulated DCs, the levels of GSK3 3 -mediated phospho-GS were substantially reduced $(<42 \%)$ after IFN b stimulation (Fig. 14A-B). Moreover, treatment of DCs with the

GSK3 inhibitor SB216763 completely abrogated GS phosporylation as evident by the $100 \%$ reduction in the phosphorylation levels of GS, as compared to non-stimulated controls (Fig. 14A-B). Thus, whereas IFN $\beta$-stimulated DC did exhibit a partial 
reduction in GSK3 activity, it did not completely abolish the activity of GSK3, as noted with the GSK3 inhibitor SB216763.

\section{IFN- $\beta$ enhances the activity of the transcription factor CREB}

The present study demonstrated that IFN- $\beta$ was capable of reducing GSK3bactivity and that this process was critical for the ability of IFN- $\beta$ to induce IL- 10 by human DCs. Since GSK3- $\beta$ has previously been shown to regulate the activity of the transcription factor CREB and that CREB is involved in regulating IL-10 production by TLR-stimulated cells, we next investigated whether IFN- $\beta$-mediated GSK3 inhibition influenced the nuclear levels of CREB (Ser 133). We have previously demonstrated that the inhibition of GSK $3 \beta$ activity by way of TLR-stimulation leads to an increase in the level of nuclear phospho-CREB at serine133. The phosphorylatio of this site has previously been demonstrated to enhance CREB's interaction with the transcription coactivator CBP. As compared to non-stimulated control, neither the GSK3 inhibitor SB216763 nor PI3K inhibitor LY294002 substantially affected the levels of nuclear phosphorylated CREB (Ser 133) in non-stimulated cells (Fig. 14C). In contrast, the DNA binding properties of CREB (Ser 133) were significantly $(\mathrm{P}<0.01)$ enhanced in IFN- $\beta$ stimulated DC, as compared to non-stimulated control cells (Fig. 14C). Moreover, cells pre-treated with the GSK3 inhibitor SB216763 significantly $(\mathrm{P}<0.01)$ enhanced the nuclear levels of CREB(Ser133), whereas blockade of PI3K activity abrogated the ability of IFN- $\beta$ to increase $\mathrm{CREB}(\operatorname{Ser} 133)$ DNA-binding activity, as compared to cells stimulated with IFN- $\beta$ (Fig. 14C). These findings demonstrate that the ability of IFN- $\beta$ to augment the nuclear levels and DNA binding of CREB (Ser133) are dependent upon its engagement of the PI3K pathway and its ability to suppress GSK3 activity. 


\section{$\underline{\text { Discussion }}$}

The ability of IFN- $\beta$ to induces the anti-inflammatory cytokine IL-10 is believed to play a critical role in its therapeutic value for the treatment of MS $(100,105)$. Although previous studies have documented a multitude of signaling cascades that can be activated by IFN- $\beta$ including the Jak-STAT, PI3K, P38, MAPKs and NF-KB pathways, the cellular mechanisms responsible for the ability of IFN- $\beta$. to stimulate the production of IL-10 has remained largely unknown $(97,125,126,136)$. Our present findings demonstrated that IFN- $\beta$ activates the PI3K pathway and that this process is required for IFN- $\beta$ induces IL-10 production. Moreover, we demonstrated that IFN- $\beta$ is able to regulate the activity of the constitutively active serine/threonine kinase GSK3-ba downstream signaling component within the PI3K pathway, and that the suppression of GSK3 activity is required for IFN- $\beta$ to induce IL-10 from human DCs.

GSK $3-\beta$ is a constitutively activated serine/threonine kinase within the PI3K pathway (50). Past studies have shown that inhibiting its GSK3 kinase activity negatively influences the levels of proinflammatory cytokines while concurrently augmenting the level of the anti-inflammatory cytokine IL-10 in TLR-stimulated cells (60). A recent study by Cheng et al. (101) has shown that IFN- $\beta$ produced upon LPS stimulation was required for LPS-induced IL-10. However, the underlying cell-signaling pathway engaged by this positive feedback loop responsible for IL-10 induction was not clear. The findings of the current study extend Chang et al's findings by demonstrating that the ability of IFN- $\beta$ to partially repress GSK3- $\beta$ activity is a necessary step in the induction of IL-10 upon IFN- $\beta$ stimulation. Indeed, preventing the phospho-inactivation 
of GSK3- $\beta$ either by blocking PI3K activity or by the overexpression of a constitutively active mutant of GSK3-b(S9A) inhibited the ability of IFN- $\beta$ to stimulate IL-10 production from human DCs. Moreover, the observed higher levels of IL-10 induced by IFN- $\beta$ stimulation in the presence of GSK3 inhibition, as compared to IFN- $\beta$ alone, suggested IFN- $\beta$ stimulation reduces rather than abolishes the cellular pool of activate GSK3. Indeed, an assessment of endogenous GSK3 activity by measuring the levels of phospho-glycogen synthase revealed that IFN- $\beta$ is incapable of fully inactivating GSK3 in human DCs. Thus, although IFN- $\beta$ mediated suppression of GSK3 activity is responsible for IFN- $\beta$ 's ability to induce IL-10, this effect on IL-10 production can be further modulated by other stimuli that can further repress GSK3 activity.

Type I IFNs have been shown to play a crucial role in host defenses against various pathogenic bacteria by differentially modulating the production of some important immunomodulatory cytokines (137) (138) (139). Past studies have shown that type I IFNs can inhibit the production of IL-12 and enhance the immunosuppressive cytokine IL-10 in vitro and in vivo $(99,104,140)$. It has additionally been shown that IFNAR deficient mice exhibited a hyperinflammatory response in vivo to LPS challenge and had significantly lower levels of IL-10, as compared to wild-type mice $(141,142)$. Since IL-10 is a well-known immunosuppressive cytokine and plays a crucial role in modulating the immune response against various pathogenic bacteria $(98,143-145)$, our current findings identifying how IFN- $\beta$ induces IL-10 production by way of GSK3- $\beta$ coupled with our previous work demonstrating the ability of GSK3- $\beta$ to differentially regulate IL-10 and IL-12 levels, provides insight into the cellular mechanism responsible for the inhibitory effect of type I IFNs on the host inflammatory response. 
In conclusion, the present study identified that IFN- $\beta$ activated the PI3K pathway and induced the partial inactivation of the constitutively active serine/threonine kinase, GSK3- $\beta$. This process was found to play a critical role in the regulation of the antiinflammatory cytokine IL- 10 production by IFN- $\beta$-stimulated DCs. Interestingly, the cell-signaling pathway by which IFN- $\beta$ suppresses GSK3 activity appeared to be selective for the induction of IL-10, and thus mimics some of the characteristics GSK3 plays in enhancing IL-10 production by TLR-stimulated innate immune cells. The current findings further characterized and identified the underlying cellular mechanisms by which IFN- $\beta$ induces the production of IL-10 by innate immune cells and underscored the importance of GSK3 regulation in the induction of IL-10 by IFN- $\beta$. Since IFN- $\beta$ treatment has been shown to increase the serum levels of IL-10 present in MS patients (100), and this effect is believed to play an important role in the therapeutic value of type I IFNs in the treatment of MS patients (105), our results indicate that GSK3 inhibition may be a therapeutic target candidate for enhancing the therapeutic value of systemically administered IFN- $\beta$. 


\section{Figure 8}
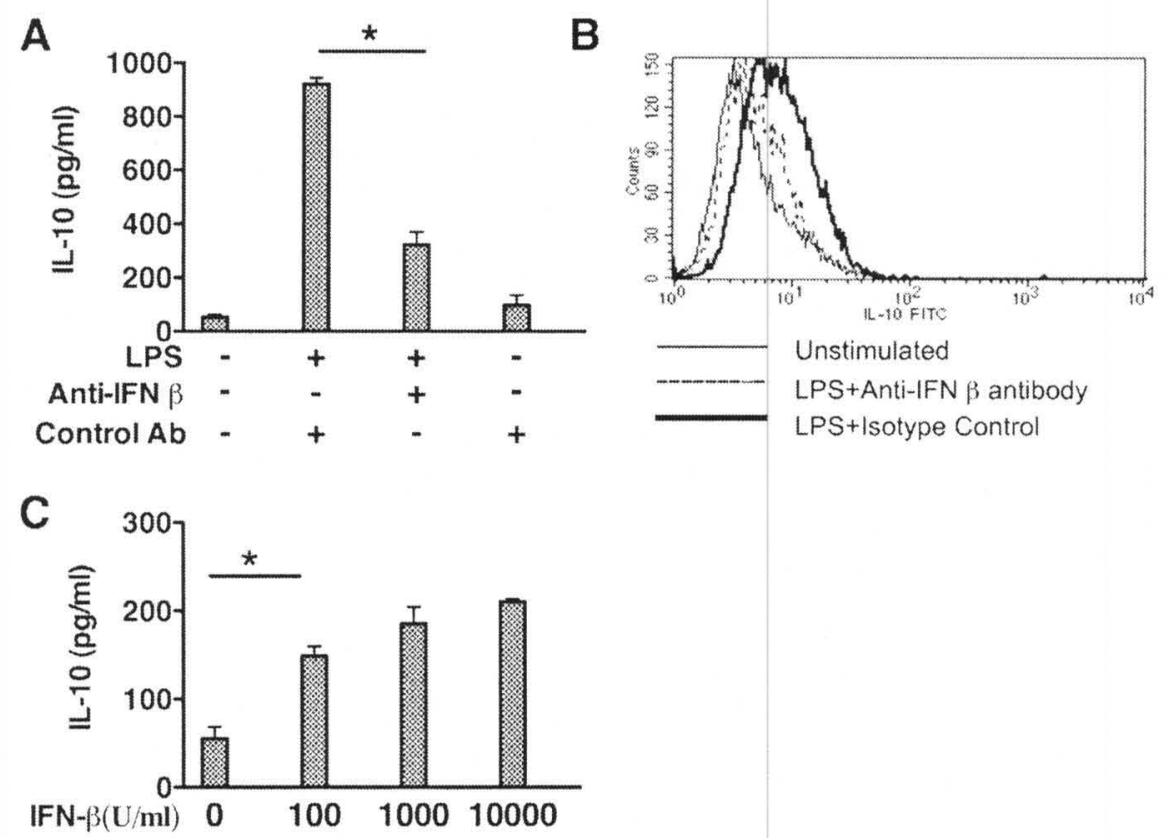

Figure 8. IFN- $\beta$ is required for LPS-induced IL-10 production from DCs. (A) DCs were pretreated with anti-IFN $\beta$ or isotype control antibody $(100 \mathrm{ng} / \mathrm{ml})$ for $2 \mathrm{~h}$, stimulated for $20 \mathrm{~h}$ with or without LPS $(1 \mu \mathrm{g} / \mathrm{ml})$, and cell-free supernatants were analyzed for IL10 levels by ELISA. (B) DCs were pretreated with anti-IFN $\beta$ or isotype control antibody for $2 \mathrm{~h}$ and then stimulated with LPS $(1 \mu \mathrm{g} / \mathrm{ml})$ for $20 \mathrm{~h}$. Monensin was added during the last $12 \mathrm{~h}$ of the assay and cells were analyzed for intracellular IL-10 by flow cytometry. (C) DCs were stimulated with the indicated concentration of IFN- $\beta$ for $24 \mathrm{~h}$ and cell-free supernatants were analyzed for IL-10 by ELISA. ${ }^{*}, p<0.01$ as determined by ANOVA and post hoc Tukey test. Data represent the mean $\pm \mathrm{SD}$ of three separate experiments. 


\section{Figure 9}
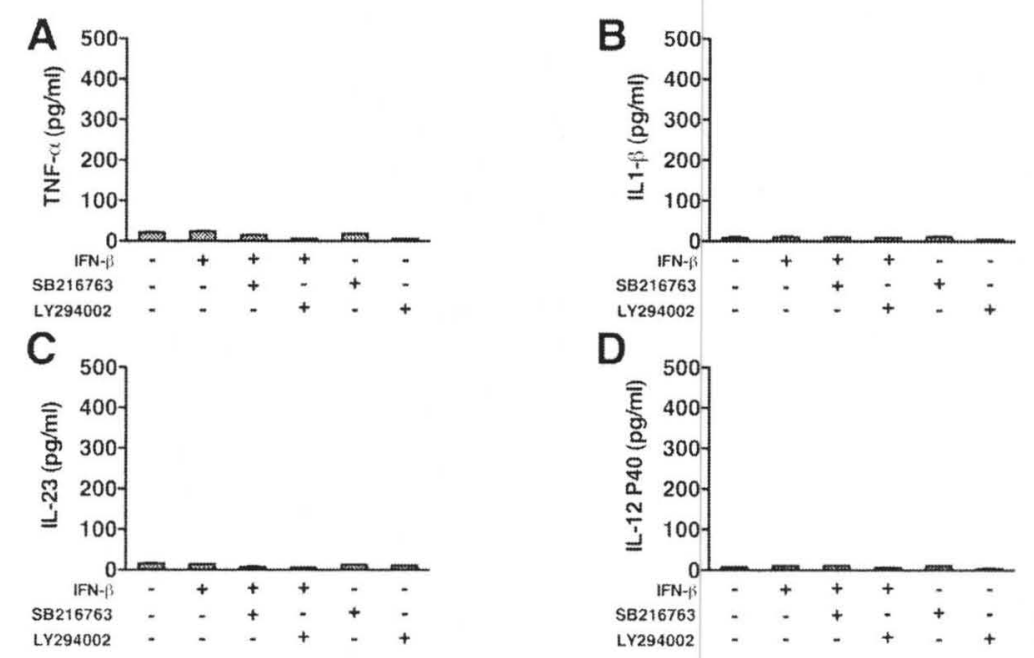

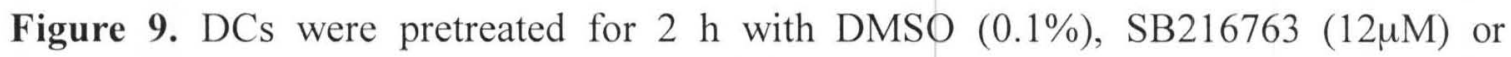
LY294002 $(50 \mu \mathrm{M})$ and then stimulated with IFN- $\beta(5000 \mathrm{IU} / \mathrm{ml})$. Cell-free supernatants were collected $20 \mathrm{~h}$ after IFN $\beta$ stimulation and assayed for TNF- $\alpha$ (D), IL-1 $\beta$ (E), IL-23 (F), and IL-12p40 (G) levels by ELISA. *,$p<0.01$ as determined by ANOVA and post hoc Tukey test. Data represent the mean $\pm \mathrm{SD}$ of three separate experiments. 


\section{Figure 10}

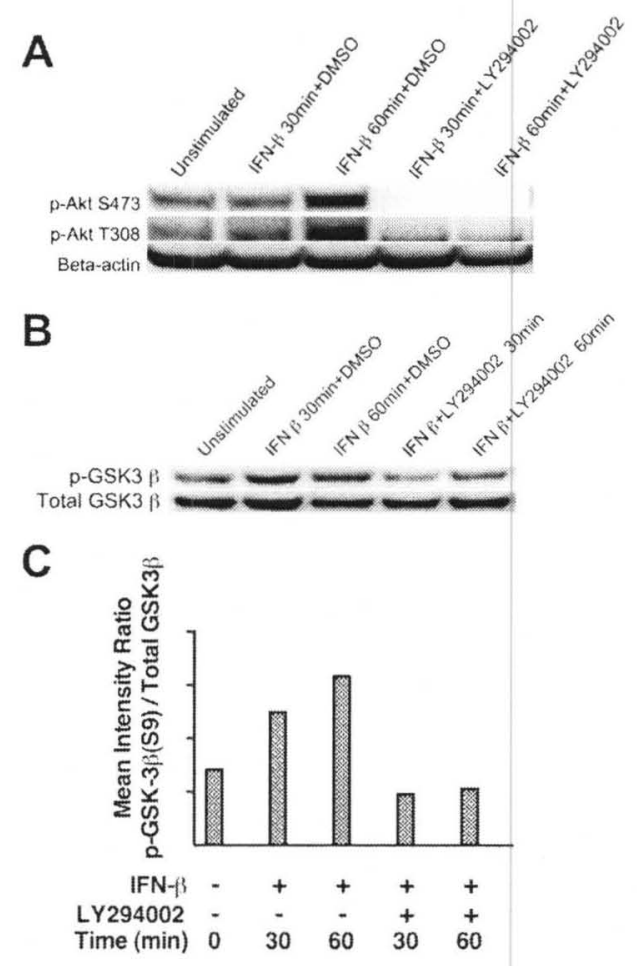

Figure 10. IFN- $\beta$ induces PI3K-dependent phosphorylation of Akt and GSK3 $\beta$ in

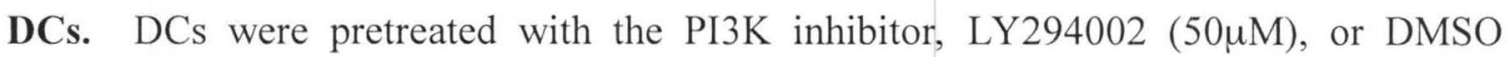
$(0.1 \%)$ for $2 \mathrm{~h}$ and then stimulated with IFN- $\beta$ for 30 or $60 \mathrm{~min}$. Total cell lysates were probed for phospho-Akt (S473 or T308) (A) or phospho-GSK3ß (S9) (B) levels by Western blot and subsequently reprobed for total GSK3- $\beta$ and total $\beta$-actin. (C) Densitometry scans of total and phospho-GSK3 $\beta$ (S9) were performed and recorded as the ratio of phospho-GSK3 $\beta$ (S9) to total GSK3 $\beta$. Data are representative of three separate experiments. 


\section{Figure 11}
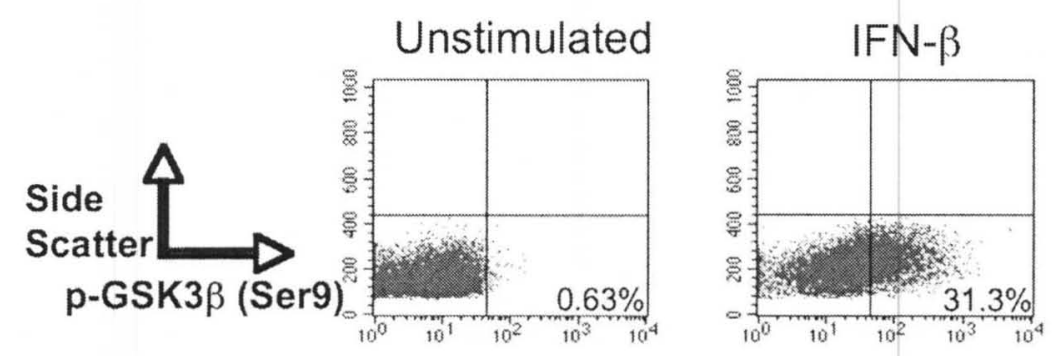

IFN- $\beta+\mathrm{LY} 294002$

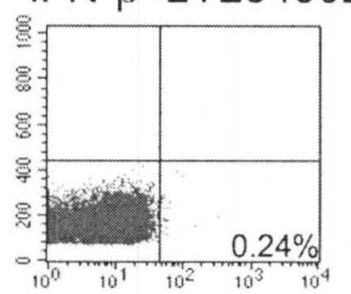

Figure 11. DCs were pretreated for $2 \mathrm{~h}$ with LY294002 $(50 \mu \mathrm{M})$ or DMSO $(0.1 \%)$ and then stimulated with IFN- $\beta$ for $60 \mathrm{~min}$ and the levels of phospho-GSK3 $\beta$ (S9) were analyzed by flow cytometry. Data are representative of three separate experiments. 


\section{Figure 12}

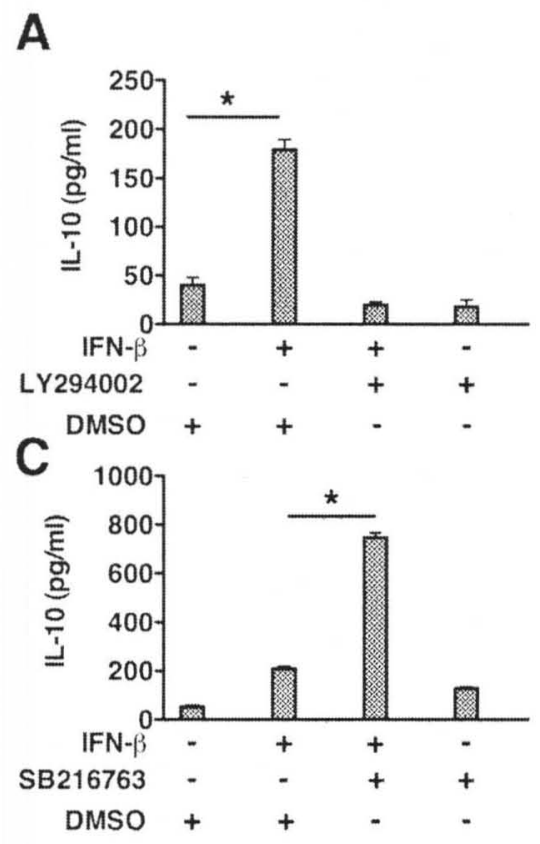

B
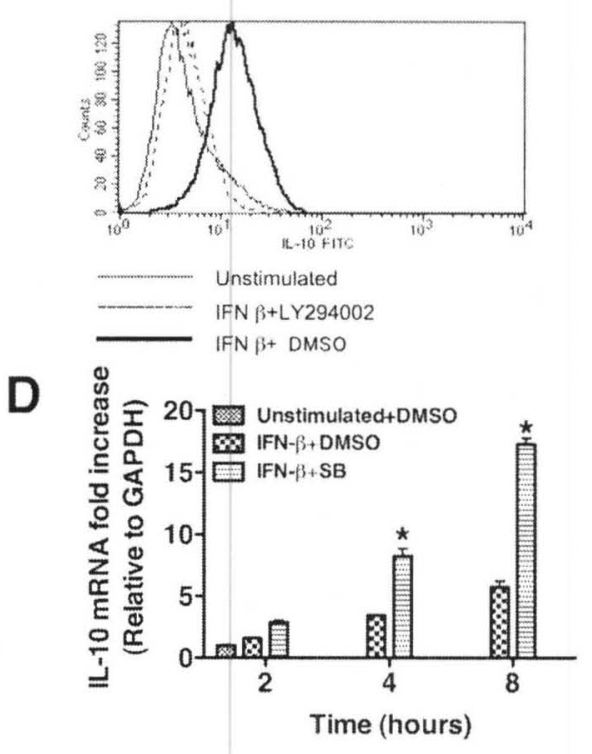

Figure 12. Regulation of IFN- $\beta$ induced IL-10 production by PI3K and GSK3. (A) DCs were pretreated for $2 \mathrm{~h}$ with DMSO (0.1\%) or LY294002 $(50 \mu \mathrm{M})$ and then stimulated with IFN $\beta(5000 \mathrm{IU} / \mathrm{ml})$ for $20 \mathrm{~h}$ with the resultant. Cell-free supernatants were analyzed for IL-10 levels by ELISA. (B) DCs were stimulated as indicated above with the exception that monesin was added during the last 12 hours of stimulation and cells were subsequently analyzed for intracellular IL-10 by flow cytometry. (C and D)

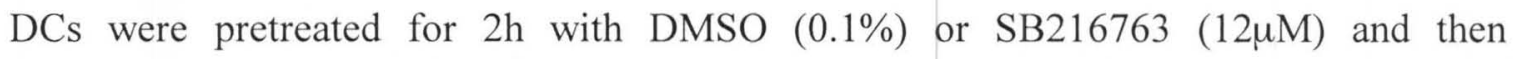
stimulated with IFN- $\beta$. IL-10 protein and steady-state mRNA levels were determined by ELISA following a $20 \mathrm{~h}$ stimulation and by RT-PCR, respectively. $*, p<0.01$ as determined by ANOVA and post hoc Tukey test. Data represent the mean $\pm \mathrm{SD}$ of three separate experiments. 


\section{Figure 13}

A
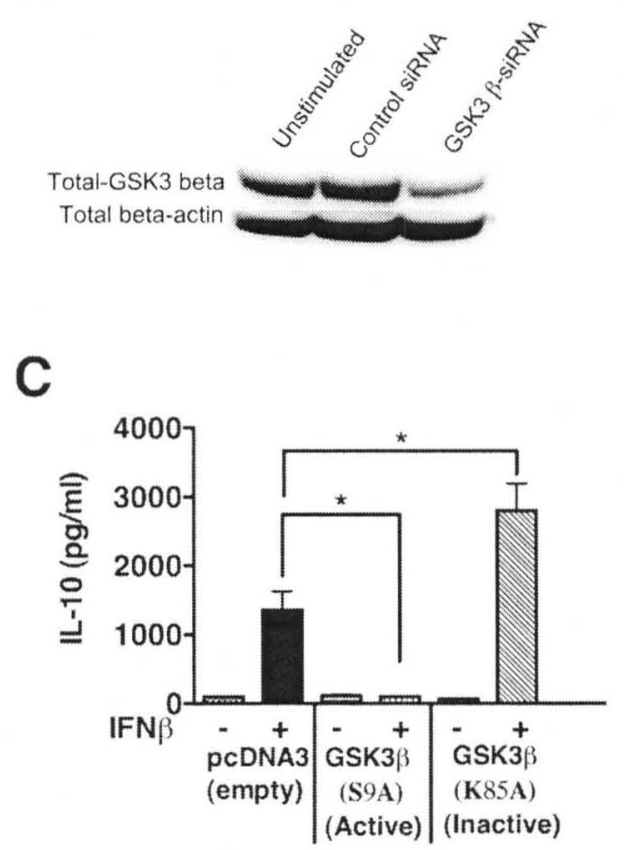

B

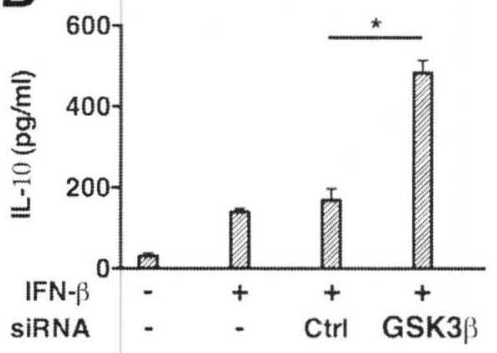

Figure 13. IFN- $\beta$ induced IL-10 production is dependent on GSK3 $\beta$ activity. (A) DCs were either mock transfected, transfected with nontargeting siRNA, or transfected with GSK3 $\beta$-specific siRNA. Cellular lysates were prepared and day 3 and analyzed by Western blot. (B) Transfected cells were stimulated with IFN- $\beta$ and IL-10 levels from cell-free supernatants were analyzed by ELISA. (C) DCs were transfected with pcDNA3 (empty vector control), pDNA3 encoding a constitutively active mutant of GSK3- $\beta$ (S9A), or pcDNA3 encoding a kinase dead mutant of GSK3- $\beta$ (K85A). On day 2, transfected cells were stimulated for $20 \mathrm{~h}$ with IFN- $\beta$ and IL-10 levels from cell-free supernatants were analyzed by ELISA. ${ }^{*}, p<0.01$ as determined by ANOVA and post hoc Tukey test. Data represent the mean $\pm \mathrm{SD}$ of three separate experiments. 


\section{Figure 14}

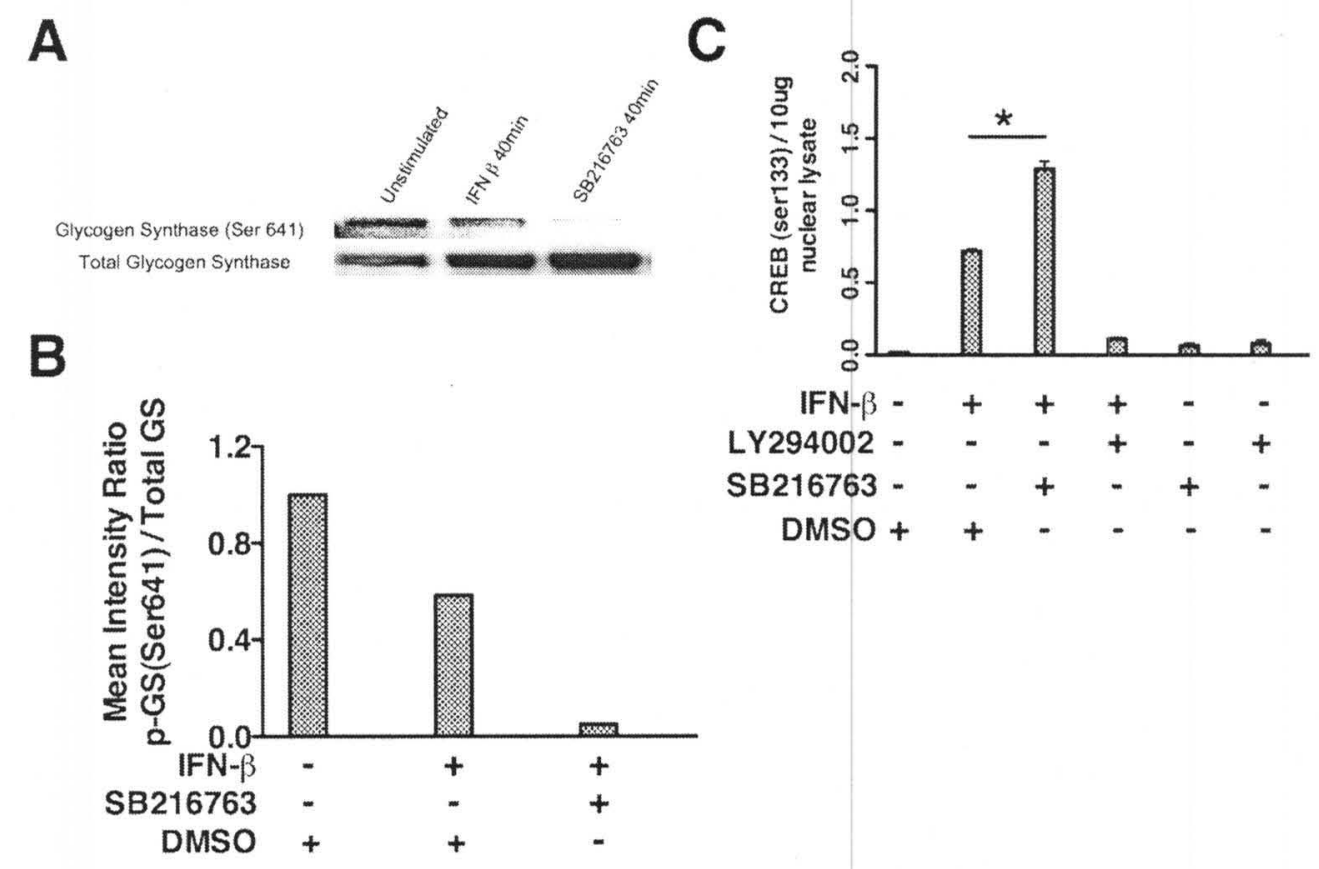

Figure 14. IFN- $\beta$ stimulation of DCs alters the phospho-levels of the GSK3 $\beta$ substrates glycogen synthase and CREB. DCs were pretreated with DMSO (0.1\%), the GSK3 inhibitor SB216763 $(12 \mu \mathrm{M})$, or the PI3K inhibitor LY294002 (50 $\mu \mathrm{m})$ and then stimulated with IFN- $\beta$. (A) Cells was harvested after 30 min stimulation and probed for phospho-Glycogen Synthase (Ser641) and $\beta$-actin by Western blot. (B) Densitometer scans of blots from Figure 14A. (C) Nuclear extracts $(10 \mu \mathrm{g})$ were prepared from DCs after IFN $\beta$ stimulation and analyzed for binding activity of CREB using an ELISA-based transcription factor binding assay. ${ }^{*}, p<0.01$ as determined by ANOVA and post hoc Tukey test. Data represent the mean $\pm \mathrm{SD}$ of three separate experiments. 
MODEL FOR GSK3'S REGULATION OF IFN BETA SIGNALING

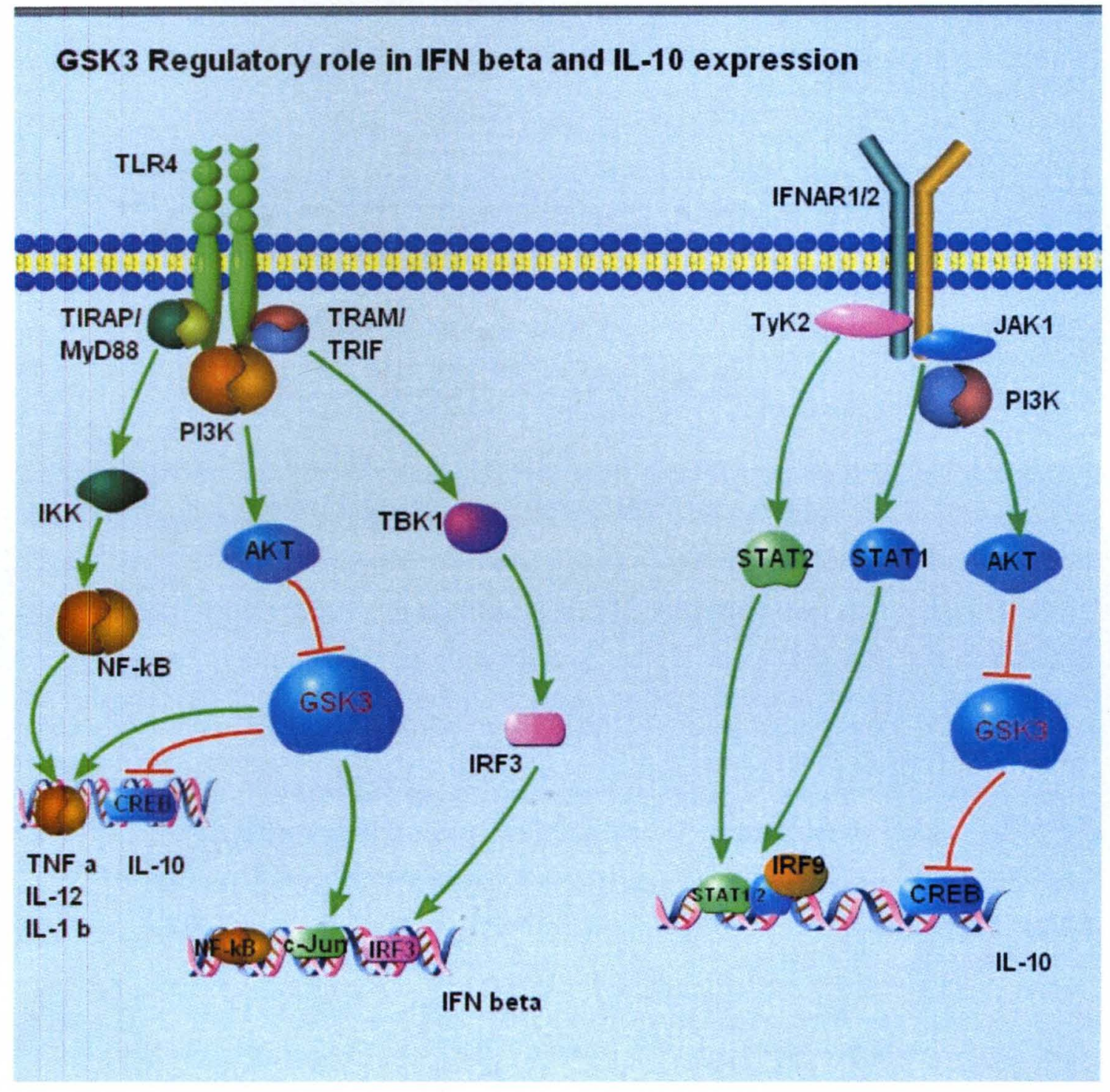




\section{CHAPTER IV CONCLUSIONS}

TLRs initiate various signal transduction cascades that activate and regulate the host's immune response. As a result, a common set of genes are expressed which produce essential molecules for the activation and the regulation of both innate and adaptive immunity, such as pro- and anti- inflammatory cytokines, chemokines and costimulatory molecules (146-148). This resultant inflammatory response is essential for the eradication of infectious microorganisms. However, excessive or prolonged activation of TLRs can lead to detrimental inflammatory reactions, tissue/cell damage, and even death (149). Therefore, it is crucial to identify and characterize specific regulatory molecules and pathways involved in controlling the host inflammatory response. The work presented herein identified two new regulatory pathways that characterized the cellular processes by which GSK3 regulates the production of the prototypical MyD88independent cytokine, IFN $\beta$, as well as how IFN $\beta$ acts via a autocrine/paracrine feedback mechanism to induce IL-10 production by innate immune cells.

GSK3- $\beta$ is a constitutively activated serine/threonine kinase within the PI3K pathway (50). Past studies have shown that inhibition of GSK3 kinase activity negatively influences the levels of proinflammatory cytokines while concurrently augmenting the level of the anti-inflammatory cytokine IL-10 produced by TLR-stimulated cells 
(60). A recent study by Cheng et al. (101) has shown that IFN- $\beta$ was involved in the production of IL-10 by LPS-stimulated cells due to a positive feedback mechanism involving IFN $\beta$. The findings of the current study extend these findings by demonstrating that the ability of IFN- $\beta$ to partially repress GSK3- $\beta$ activity was necessary for the induction of IL-10 by IFN- $\beta$ stimulated cells. Preventing the phosphoinactivation of GSK3- $\beta$ inhibited the ability of IFN $-\beta$ to stimulate IL -10 production from DC. The observed increase in the levels of IL-10 induced by IFN- $\beta$ in the presence of GSK3 inhibition, as compared to IFN- $\beta$ alone, suggested IFN- $\beta$ alone may not have inactivated GSK3 to the levels mediated by the GSK3 inhibitor. Indeed, an assessment of GSK3 inactivation revealed that IFN- $\beta$ was capable of partially inactivating the ability of GSK3 to phosphorylate a specific GSK3 substrate, as compared to complete inhibition observed with the GSK3 inhibitor. Thus, IFN- $\beta$ mediated suppression in GSK3 activity is responsible for its ability to induce IL-10, and this effect on IL-10 production can be further enhanced by inactivating GSK3 activity.

The identification and characterization of the downstream cell-signaling events regulating the IFN- $\beta$ response have been shown to involve the activation of the kinases TBK-1 and IKK- $\varepsilon$ that are involved in the phosphorylation of the transcription factor IRF-3 and its subsequent dimerization and translocation into the nucleus (35) (121) (122). In addition to IRF-3, studies analyzing the inf $\beta$ promoter have revealed the presence of additional regulatory molecules that can bind one of the four positive regulatory domains within the ifn $\beta$ promoter. In this regard, ATF-2 and c-Jun have been shown to bind the if $n \beta$ promoter via a heterodimeric complex within the positive regulatory domain IV of the ifn $\beta$ promoter (116) (86) (91). Although the findings of the present study did not 
observe any discernible effects of GSK3 inhibition on the activity of IRF-3, the ability of GSK3 to regulate the cellular levels of c-Jun were found to be of critical importance for the ability of GSK3 to modulate IFN- $\beta$ production by LPS-stimulated innate immune cells. Moreover, siRNA-mediated knockdown of c-Jun levels in macrophages reduced the levels of IFN- $\beta$ produced by cells stimulated with LPS. These findings demonstrate a fundamental role for c-Jun in the regulation of IFN- $\beta$ and highlight the underlying molecular mechanism by which GSK 3 regulates IFN- $\beta$ by LPS stimulated innate immune cells.

Past studies have shown that type I IFNs could inhibit the production of IL-12 and enhance the immunosuppressive cytokine IL-10 in vitro and in vivo $(99,104,140)$. It has additionally been shown that IFNAR deficient mice exhibited a hyper-inflammatory response in vivo to LPS challenge and had significantly lower levels of IL-10, as compared to wild-type mice $(141,142)$. Since IL-10 is a well-known immunosuppressive cytokine and plays a crucial role in modulating the immune response against various pathogenic bacteria $(98,143-145)$, our current findings identifying how IFN- $\beta$ induced IL-10 production is mediated via partial inhibition of GSK3- $\beta$ and the ability of GSK3- $\beta$ to differentially regulate IL-10 and IL-12 levels, provides insight into the cellular mechanism responsible for the inhibitory effect of type I IFNs on the host inflammatory response.

There are two major molecular pathways activated by TLR 4 and are classified as MyD88-dependent and MyD88-independent $(31,33,110)$. Previous studies by our laboratory and others demonstrated that $\operatorname{GSK} 3 \beta$, a downstream serine-threonine kinase within the PI3K pathway, differentially regulates the levels of MyD88-dependent 
cytokines, including both pro- and anti-inflammatory cytokines by TLR4-mediated innate immune cells (60). Specifically, the inactivation of GSK3- $\beta$ was shown to negatively influence the levels of pro-inflammatory cytokines while concurrently augmenting the levels of the anti-inflammatory cytokine IL-10 in response to TLR4-stimulation (60). The current findings extend these observations by demonstrating that the inactivation of GSK3- $\beta$ (Ser9) occurs in the absence of MyD88 and that GSK3- $\beta$ activity was a critical component of the regulatory mechanism that controlled the levels of IFN- $\beta$ by TLR4stimulated cells both in vitro and in vivo. Interestingly, the cellular mechanisms by which GSK3 regulated the prototypical MyD88-independent cytokine, IFN- $\beta$, differed from that by which GSK3 regulates the production of MyD88-dependent pro- and antiinflammatory cytokines. In the current study, we showed that the inhibition of GSK3 $\beta$ augmented the levels of the transcription factor c-Jun and thereby increased the amount of c-Jun /ATF2 complexes that were responsible for the ability of GSK3 inhibition to augment the production of IFN $\beta$. In contrast, GSK3 differentially regulated the production of MyD88-dependent cytokines via increases in nuclear levels of CREB (S133) and thus enhanced the formation of the transcriptional complex CREB/CBP that promoted the transcriptional regulation of IL-10 while attenuating the production of NF$\kappa \mathrm{B}$-dependent pro-inflammatory cytokines (60). Taken together, these studies highlighted the capacity of GSK3 $\beta$ to regulate both MyD88-dependent $(112,113,119)$ and MyD88-independent cytokine responses and further characterized the fundamental role that GSK3- $\beta$ played in the regulation of the host inflammatory response.

IL-10 has long been recognized to be a prototypical immunosuppressive cytokine and involved in the regulation of immune homeostasis due to its broad anti-inflammatory 
properties on cells of both innate and adaptive immune system (98). Dys-regulation of IL-10 has been shown to mediate or contribute to many chronic inflammatory diseases such as Chrohn's disease, multiple sclerosis, and allergic contact dermatitis (150). There are several aspects of IL-10 gene regulation that are conserved among all cells, while other mechanisms appear to be cell-type specific $(151,152)$. In this regard, the promoter region in all IL-10-producing cells is essentially the same and the transcription factors that initiate IL-10 transcription are conserved (152). Transcription factors reported to bind the IL-10 promoter include Sp1/3, STAT3, C/EBP, IRF-1, c-Maf, AP-1, CREB, and NF-KB (152). In contrast to these conserved transcription factors, the signaling pathways that induce IL-10 are generally unique to each cell type. In innate immune cells, several studies have shown that GSK3 regulated the production of IL-10 in a CBP-CREB dependent manner in which GSK3 inactivation increases the nuclear levels of CREB (S133) and displaces NF-kB p65 from the transcriptional complex. Subsequent studies have also shown that the Epstein Barr Viral Protein, LMP1, induces IL-10 production from B cells through the inactivation of GSK3 and an increase in CREB activity (153). Studies by others have confirmed these initial observations by demonstrating that GSK3 activity regulated the IL-10 production in response to stimulation by Anti-ribosomal phosphoprotein autoantibodies in both macrophage cell-lines and primary human macrophages (130). In contrast, the cellular mechanism by which GSK3 controls IL-10 production in human memory $\mathrm{CD} 4{ }^{+} \mathrm{T}$ cells is divergent. Specifically, GSK3 inactivation potently increases IL-10 production by memory $\mathrm{CD}^{+} \mathrm{T}$ cells by increasing the cellular levels of the transcription factor, c-Jun. Interestingly, GSK3 inactivation in memory $\mathrm{CD}^{+} \mathrm{T}$ cells exhibited no effect on the nuclear levels or transcriptional binding 
properties of CREB (S133) (154). Thus, the ability of GSK3 to regulate the production of IL-10 appears to be conserved among cells comprising both the innate and adaptive immune compartments. However, the underlying cellular mechanisms by which GSK3 controls IL-10 production in different cellular lineages differ. 


\section{REFERENCES}

1. Janeway, C. A., Jr., and R. Medzhitov. 2002. Innate immune recognition. Annu Rev Immunol 20:197-216.

2. Medzhitov, R. 2001. Toll-like receptors and innate immunity. Nat Rev Immunol 1:135-145.

3. Meylan, E., J. Tschopp, and M. Karin. 2006. Intracellular pattern recognition receptors in the host response. Nature 442:39-44.

4. Hashimoto, C., K. L. Hudson, and K. V. Anderson. 1988. The Toll gene of Drosophila, required for dorsal-ventral embryonic polarity, appears to encode a transmembrane protein. Cell 52:269-279.

5. Lemaitre, B., E. Nicolas, L. Michaut, J. M. Reichhart, and J. A. Hoffmann. 1996. The dorsoventral regulatory gene cassette spatzle/Toll/cactus controls the potent antifungal response in Drosophila adults. Cell 86:973-983.

6. Marshak-Rothstein, A., and I. R. Rifkin. 2007. Immunologically active autoantigens: the role of toll-like receptors in the development of chronic inflammatory disease. Annu Rev Immunol 25:419-441.

7. Tabeta, K., P. Georgel, E. Janssen, X. Du, K. Hoebe, K. Crozat, S. Mudd, L. Shamel, S. Sovath, J. Goode, L. Alexopoulou, R. A. Flavell, and B. Beutler. 2004. Toll-like receptors 9 and 3 as essential components of innate immune defense against mouse cytomegalovirus infection. Proc Natl Acad Sci US A 101:35163521 .

8. Takeda, K., T. Kaisho, and S. Akira. 2003. Toll-like receptors. Annu Rev Immunol 21:335-376.

9. Zhang, D., G. Zhang, M. S. Hayden, M. B. Greenblatt, C. Bussey, R. A. Flavell, and S. Ghosh. 2004. A toll-like receptor that prevents infection by uropathogenic bacteria. Science 303:1522-1526.

10. O'Neill, L. A., and A. G. Bowie. 2007. The family of five: TIR-domaincontaining adaptors in Toll-like receptor signalling. Nat Rev Immunol 7:353-364.

11. Akira, S., S. Uematsu, and O. Takeuchi. 2006. Pathogen recognition and innate immunity. Cell 124:783-801. 
12. Ishii, K. J., S. Uematsu, and S. Akira. 2006. 'Toll' gates for future immunotherapy. Curr Pharm Des 12:4135-4142.

13. Akashi-Takamura, S., and K. Miyake. 2006. Toll-like receptors (TLRs) and immune disorders. J Infect Chemother 12:233-240.

14. Carpenter, S., and L. A. O'Neill. 2007. How important are Toll-like receptors for antimicrobial responses? Cell Microbiol 9:1891-1901.

15. Uematsu, S., M. H. Jang, N. Chevrier, Z. Guo, Y. Kumagai, M. Yamamoto, H. Kato, N. Sougawa, H. Matsui, H. Kuwata, H. Hemmi, C. Coban, T. Kawai, K. J. Ishii, O. Takeuchi, M. Miyasaka, K. Takeda, and S. Akira. 2006. Detection of pathogenic intestinal bacteria by Toll-like receptor 5 on intestinal CD11c+ lamina propria cells. Nat Immunol 7:868-874.

16. Lauw, F. N., D. R. Caffrey, and D. T. Golenbock. 2005. Of mice and man: TLR11 (finally) finds profilin. Trends Immunol 26:509-511.

17. Yarovinsky, F., and A. Sher. 2006. Toll-like receptor recognition of Toxoplasma gondii. Int J Parasitol 36:255-259.

18. Kawai, T., and S. Akira. 2007. Antiviral signaling through pattern recognition receptors. J Biochem 141:137-145.

19. Krieg, A. M., and J. Vollmer. 2007. Toll-like receptors 7, 8, and 9: linking innate immunity to autoimmunity. Immunol Rev 220:251-269.

20. Gorden, K. K., X. Qiu, J. J. Battiste, P. P. Wightman, J. P. Vasilakos, and S. S. Alkan. 2006. Oligodeoxynucleotides differentially modulate activation of TLR7 and TLR8 by imidazoquinolines. $J$ Immunol 177:8164-8170.

21. Wright, S. D., R. A. Ramos, P. S. Tobias, R. J. Ulevitch, and J. C. Mathison. 1990. CD14, a receptor for complexes of lipopolysaccharide (LPS) and LPS binding protein. Science 249:1431-1433.

22. Guha, M., and N. Mackman. 2001. LPS induction of gene expression in human monocytes. Cell Signal 13:85-94.

23. Erridge, C., S. Kennedy, C. M. Spickett, and D. J. Webb. 2008. Oxidized phospholipid inhibition of toll-like receptor (TLR) signaling is restricted to TLR2 and TLR4: roles for CD14, LPS-binding protein, and MD2 as targets for specificity of inhibition. $J$ Biol Chem 283:24748-24759.

24. Shimazu, R., S. Akashi, H. Ogata, Y. Nagai, K. Fukudome, K. Miyake, and M. Kimoto. 1999. MD-2, a molecule that confers lipopolysaccharide responsiveness on Toll-like receptor 4. J Exp Med 189:1777-1782.

25. Dunne, A., and L. A. O'Neill. 2003. The interleukin-1 receptor/Toll-like receptor 
superfamily: signal transduction during inflammation and host defense. Sci STKE 2003:re3.

26. O'Neill, L. A., K. A. Fitzgerald, and A. G. Bowie. 2003. The Toll-IL-1 receptor adaptor family grows to five members. Trends Immunol 24:286-290.

27. Yamamoto, M., K. Takeda, and S. Akira. 2004. TIR domain-containing adaptors define the specificity of TLR signaling. Mol Immunol 40:861-868.

28. Moynagh, P. N. 2005. TLR signalling and activation of IRFs: revisiting old friends from the NF-kappaB pathway. Trends Immunol 26:469-476.

29. Yamamoto, M., S. Sato, K. Mori, K. Hoshino, O. Takeuchi, K. Takeda, and S. Akira. 2002. Cutting edge: a novel Toll/IL-1 receptor domain-containing adapter that preferentially activates the IFN-beta promoter in the Toll-like receptor signaling. J Immunol 169:6668-6672.

30. Kawai, T., O. Takeuchi, T. Fujita, J. Inoue, P. F. Muhlradt, S. Sato, K. Hoshino, and S. Akira. 2001. Lipopolysaccharide stimulates the MyD88-independent pathway and results in activation of IFN-regulatory factor 3 and the expression of a subset of lipopolysaccharide-inducible genes. J Immunol 167:5887-5894.

31. Hoebe, K., X. Du, P. Georgel, E. Janssen, K. Tabeta, S. O. Kim, J. Goode, P. Lin, N. Mann, S. Mudd, K. Crozat, S. Sovath, J. Han, and B. Beutler. 2003. Identification of Lps2 as a key transducer of MyD88-independent TIR signalling. Nature 424:743-748.

32. Yamamoto, M., S. Sato, H. Hemmi, K. Hoshino, T. Kaisho, H. Sanjo, O. Takeuchi, M. Sugiyama, M. Okabe, K. Takeda, and S. Akira. 2003. Role of adaptor TRIF in the MyD88-independent toll-like receptor signaling pathway. Science 301:640-643.

33. Yamamoto, M., S. Sato, H. Hemmi, S. Uematsu, K. Hoshino, T. Kaisho, O. Takeuchi, K. Takeda, and S. Akira. 2003. TRAM is specifically involved in the Toll-like receptor 4-mediated MyD88-independent signaling pathway. Nat Immunol 4:1144-1150.

34. Fitzgerald, K. A., S. M. McWhirter, K. L. Faia, D. C. Rowe, E. Latz, D. T. Golenbock, A. J. Coyle, S. M. Liao, and T. Maniatis. 2003. IKKepsilon and TBK1 are essential components of the IRF3 signaling pathway. Nat Immunol 4:491-496.

35. Sharma, S., B. R. tenOever, N. Grandvaux, G. P. Zhou, R. Lin, and J. Hiscott. 2003. Triggering the interferon antiviral response through an IKK-related pathway. Science 300:1148-1151.

36. Yoneyama, M., W. Suhara, and T. Fujita. 2002. Control of IRF-3 activation by phosphorylation. J Interferon Cytokine Res 22:73-76. 
37. Fruman, D. A., R. E. Meyers, and L. C. Cantley. 1998. Phosphoinositide kinases. Annu Rev Biochem 67:481-507.

38. Vanhaesebroeck, B., S. J. Leevers, K. Ahmadi, J. Timms, R. Katso, P. C. Driscoll, R. Woscholski, P. J. Parker, and M. D. Waterfield. 2001. Synthesis and function of 3-phosphorylated inositol lipids. Annu Rev Biochem 70:535-602.

39. Okkenhaug, K., and B. Vanhaesebroeck. 2001. New responsibilities for the PI3K regulatory subunit p85 alpha. Sci STKE 2001:PE1.

40. Vanhaesebroeck, B., and M. D. Waterfield. 1999. Signaling by distinct classes of phosphoinositide 3-kinases. Exp Cell Res 253:239-254.

41. Hazeki, K., K. Nigorikawa, and O. Hazeki. 2007. Role of phosphoinositide 3kinase in innate immunity. Biol Pharm Bull 30:1617-1623.

42. Deane, J. A., and D. A. Fruman. 2004. Phosphoinositide 3-kinase: diverse roles in immune cell activation. Annu Rev Immunol 22:563-598.

43. Cross, D. A., D. R. Alessi, P. Cohen, M. Andjelkovich, and B. A. Hemmings. 1995. Inhibition of glycogen synthase kinase-3 by insulin mediated by protein kinase B. Nature 378:785-789.

44. Frame, S., and P. Cohen. 2001. GSK3 takes centre stage more than 20 years after its discovery. Biochem J 359:1-16.

45. Jope, R. S., and G. V. Johnson. 2004. The glamour and gloom of glycogen synthase kinase-3. Trends Biochem Sci 29:95-102.

46. Woodgett, J. R. 2005. Recent advances in the protein kinase B signaling pathway. Curr Opin Cell Biol 17:150-157.

47. Doble, B. W., and J. R. Woodgett. 2003. GSK-3: tricks of the trade for a multitasking kinase. J Cell Sci 116:1175-1186.

48. Hoeflich, K. P., J. Luo, E. A. Rubie, M. S. Tsao, O. Jin, and J. R. Woodgett. 2000. Requirement for glycogen synthase kinase-3beta in cell survival and NF-kappaB activation. Nature 406:86-90.

49. Frame, S., P. Cohen, and R. M. Biondi. 2001. A common phosphate binding site explains the unique substrate specificity of GSK3 and its inactivation by phosphorylation. Mol Cell 7:1321-1327.

50. Cohen, P., and S. Frame. 2001. The renaissance of GSK3. Nat Rev Mol Cell Biol 2:769-776.

51. Kaur, S., S. Parmar, J. Smith, E. Katsoulidis, Y. Li, A. Sassano, B. Majchrzak, S. Uddin, M. S. Tallman, E. N. Fish, and L. C. Platanias. 2005. Role of protein 
kinase C-delta (PKC-delta) in the generation of the effects of IFN-alpha in chronic myelogenous leukemia cells. Exp Hematol 33:550-557.

52. Kaur, S., A. Sassano, B. Dolniak, S. Joshi, B. Majchrzak-Kita, D. P. Baker, N. Hay, E. N. Fish, and L. C. Platanias. 2008. Role of the Akt pathway in mRNA translation of interferon-stimulated genes. Proc Natl Acad Sci U S A 105:48084813.

53. Lekmine, F., S. Uddin, A. Sassano, S. Parmar, S. M. Brachmann, B. Majchrzak, N. Sonenberg, N. Hay, E. N. Fish, and L. C. Platanias. 2003. Activation of the p70 S6 kinase and phosphorylation of the 4E-BP1 repressor of mRNA translation by type I interferons. $J$ Biol Chem 278:27772-27780.

54. Dajani, R., E. Fraser, S. M. Roe, N. Young, V. Good, T. C. Dale, and L. H. Pearl. 2001. Crystal structure of glycogen synthase kinase 3 beta: structural basis for phosphate-primed substrate specificity and autoinhibition. Cell 105:721-732.

55. ter Haar, E., J. T. Coll, D. A. Austen, H. M. Hsiao, L. Swenson, and J. Jain. 2001. Structure of GSK3beta reveals a primed phosphorylation mechanism. Nat Struct Biol 8:593-596.

56. Roach, P. J. 1991. Multisite and hierarchal protein phosphorylation. J Biol Chem 266:14139-14142.

57. Fukao, T., M. Tanabe, Y. Terauchi, T. Ota, S. Matsuda, T. Asano, T. Kadowaki, T. Takeuchi, and S. Koyasu. 2002. PI3K-mediated negative feedback regulation of IL-12 production in DCs. Nat Immunol 3:875-881.

58. Guha, M., and N. Mackman. 2002. The phosphatidylinositol 3-kinase-Akt pathway limits lipopolysaccharide activation of signaling pathways and expression of inflammatory mediators in human monocytic cells. $J$ Biol Chem $277: 32124-32132$

59. Martin, M., J. Katz, S. N. Vogel, and S. M. Michalek. 2001. Differential induction of endotoxin tolerance by lipopolysaccharides derived from Porphyromonas gingivalis and Escherichia coli. J Immunol 167:5278-5285.

60. Martin, M., K. Rehani, R. S. Jope, and S. M. Michalek. 2005. Toll-like receptormediated cytokine production is differentially regulated by glycogen synthase kinase 3. Nat Immunol 6:777-784.

61. Pestka, S., C. D. Krause, and M. R. Walter. 2004. Interferons, interferon-like cytokines, and their receptors. Immunol Rev 202:8-32.

62. Berzsenyi, M. D., S. K. Roberts, and M. R. Beard. 2006. Genomics of hepatitis B and $\mathrm{C}$ infections: diagnostic and therapeutic applications of microarray profiling. Antivir Ther 11:541-552. 
63. Lam, S., S. Wang, and M. Gottesman. 2008. Interferon-betalb for the treatment of multiple sclerosis. Expert Opin Drug Metab Toxicol 4:1111-1117.

64. Maher, S. G., A. L. Romero-Weaver, A. J. Scarzello, and A. M. Gamero. 2007. Interferon: cellular executioner or white knight? Curr Med Chem 14:1279-1289.

65. Battaglia, A. M., and K. O. Hagmeyer. 2000. Combination therapy with interferon and ribavirin in the treatment of chronic hepatitis $\mathrm{C}$ infection. Ann Pharmacother $34: 487-494$.

66. Fritz, E., and H. Ludwig. 2000. Interferon-alpha treatment in multiple myeloma: meta-analysis of 30 randomised trials among 3948 patients. Ann Oncol 11:14271436.

67. Kieseier, B. C., H. Wiendl, B. Hemmer, and H. P. Hartung. 2007. Treatment and treatment trials in multiple sclerosis. Curr Opin Neurol 20:286-293.

68. Bogdan, C. 2000. The function of type I interferons in antimicrobial immunity. Curr Opin Immunol 12:419-424.

69. Baccala, R., K. Hoebe, D. H. Kono, B. Beutler, and A. N. Theofilopoulos. 2007. TLR-dependent and TLR-independent pathways of type I interferon induction in systemic autoimmunity. Nat Med 13:543-551.

70. Kawai, T., and S. Akira. 2008. Toll-like receptor and RIG-I-like receptor signaling. Ann N Y Acad Sci 1143:1-20.

71. Alexopoulou, L., A. C. Holt, R. Medzhitov, and R. A. Flavell. 2001. Recognition of double-stranded RNA and activation of NF-kappaB by Toll-like receptor 3 . Nature 413:732-738.

72. Hemmi, H., T. Kaisho, O. Takeuchi, S. Sato, H. Sanjo, K. Hoshino, T. Horiuchi, H. Tomizawa, K. Takeda, and S. Akira. 2002. Small anti-viral compounds activate immune cells via the TLR7 MyD88-dependent signaling pathway. Nat Immunol 3:196-200.

73. Jurk, M., F. Heil, J. Vollmer, C. Schetter, A. M. Krieg, H. Wagner, G. Lipford, and S. Bauer. 2002. Human TLR7 or TLR8 independently confer responsiveness to the antiviral compound R-848. Nat Immunol 3:499.

74. Heil, F., P. Ahmad-Nejad, H. Hemmi, H. Hochrein, F. Ampenberger, T. Gellert, H. Dietrich, G. Lipford, K. Takeda, S. Akira, H. Wagner, and S. Bauer. 2003. The Toll-like receptor 7 (TLR7)-specific stimulus loxoribine uncovers a strong relationship within the TLR7, 8 and 9 subfamily. Eur J Immunol 33:2987-2997.

75. Diebold, S. S., T. Kaisho, H. Hemmi, S. Akira, and C. Reis e Sousa. 2004. Innate antiviral responses by means of TLR7-mediated recognition of single-stranded RNA. Science 303:1529-1531. 
76. Heil, F., H. Hemmi, H. Hochrein, F. Ampenberger, C. Kirschning, S. Akira, G. Lipford, H. Wagner, and S. Bauer. 2004. Species-specific recognition of singlestranded RNA via toll-like receptor 7 and 8. Science 303:1526-1529.

77. Lund, J. M., L. Alexopoulou, A. Sato, M. Karow, N. C. Adams, N. W. Gale, A. Iwasaki, and R. A. Flavell. 2004. Recognition of single-stranded RNA viruses by Toll-like receptor 7. Proc Natl Acad Sci USA 101:5598-5603.

78. Bauer, S., C. J. Kirschning, H. Hacker, V. Redecke, S. Hausmann, S. Akira, H. Wagner, and G. B. Lipford. 2001. Human TLR9 confers responsiveness to bacterial DNA via species-specific CpG motif recognition. Proc Natl Acad Sci $U$ $S A$ 98:9237-9242.

79. Hemmi, H., O. Takeuchi, T. Kawai, T. Kaisho, S. Sato, H. Sanjo, M. Matsumoto, K. Hoshino, H. Wagner, K. Takeda, and S. Akira. 2000. A Toll-like receptor recognizes bacterial DNA. Nature 408:740-745.

80. Coccia, E. M., M. Severa, E. Giacomini, D. Monneron, M. E. Remoli, I. Julkunen, M. Cella, R. Lande, and G. Uze. 2004. Viral infection and Toll-like receptor agonists induce a differential expression of type I and lambda interferons in human plasmacytoid and monocyte-derived dendritic cells. Eur $J$ Immunol 34:796-805.

81. Kato, A., T. Ogasawara, T. Homma, H. Saito, and K. Matsumoto. 2004. Lipopolysaccharide-binding protein critically regulates lipopolysaccharideinduced IFN-beta signaling pathway in human monocytes. $J$ Immunol 172:61856194.

82. Toshchakov, V., B. W. Jones, P. Y. Perera, K. Thomas, M. J. Cody, S. Zhang, B. R. Williams, J. Major, T. A. Hamilton, M. J. Fenton, and S. N. Vogel. 2002. TLR4, but not TLR2, mediates IFN-beta-induced STAT1alpha/beta-dependent gene expression in macrophages. Nat Immunol 3:392-398.

83. Le, V. T., M. Trilling, A. Zimmermann, and H. Hengel. 2008. Mouse cytomegalovirus inhibits beta interferon (IFN-beta) gene expression and controls activation pathways of the IFN-beta enhanceosome. J Gen Virol 89:1131-1141.

84. Eantuzzi, L., P. Eid, W. Malorni, G. Rainaldi, M. C. Gauzzi, S. Pellegrini, F. Belardelli, and S. Gessani. 1997. Post-translational up-regulation of the cell surface-associated alpha component of the human type I interferon receptor during differentiation of peripheral blood monocytes: role in the biological response to type I interferon. Eur J Immunol 27:1075-1081.

85. Caraglia, M., G. Vitale, M. Marra, S. Del Prete, A. Lentini, A. Budillon, S. Beninati, and A. Abbruzzese. 2004. Translational and post-translational modifications of proteins as a new mechanism of action of alpha-interferon: review article. Amino Acids 26:409-417. 
86. Maniatis, T., J. V. Falvo, T. H. Kim, T. K. Kim, C. H. Lin, B. S. Parekh, and M. $\mathrm{G}$. Wathelet. 1998. Structure and function of the interferon-beta enhanceosome. Cold Spring Harb Symp Quant Biol 63:609-620.

87. Kirchhoff, S., D. Wilhelm, P. Angel, and H. Hauser. 1999. NFkappaB activation is required for interferon regulatory factor-1-mediated interferon beta induction. Eur J Biochem 261:546-554.

88. Honda, K., A. Takaoka, and T. Taniguchi. 2006. Type I interferon [corrected] gene induction by the interferon regulatory factor family of transcription factors. Immunity 25:349-360.

89. Silverman, N., and T. Maniatis. 2001. NF-kappaB signaling pathways in mammalian and insect innate immunity. Genes Dev 15:2321-2342.

90. Chu, W. M., D. Ostertag, Z. W. Li, L. Chang, Y. Chen, Y. Hu, B. Williams, J. Perrault, and M. Karin. 1999. JNK2 and IKKbeta are required for activating the innate response to viral infection. Immunity 11:721-731.

91. Panne, D., T. Maniatis, and S. C. Harrison. 2004. Crystal structure of ATF-2/cJun and IRF-3 bound to the interferon-beta enhancer. EMBO $J 23: 4384-4393$.

92. Kim, T. K., and T. Maniatis. 1997. The mechanism of transcriptional synergy of an in vitro assembled interferon-beta enhanceosome. Mol Cell 1:119-129.

93. Novick, D., B. Cohen, and M. Rubinstein. 1994. The human interferon alpha/beta receptor: characterization and molecular cloning. Cell 77:391-400.

94. Stark, G. R., I. M. Kerr, B. R. Williams, R. H. Silverman, and R. D. Schreiber. 1998. How cells respond to interferons. Annu Rev Biochem 67:227-264.

95. Biron, C. A. 2001. Interferons alpha and beta as immune regulators--a new look. Immunity 14:661-664.

96. Billiau, A. 2006. Anti-inflammatory properties of Type I interferons. Antiviral Res 71:108-116.

97. Darnell, J. E., Jr., I. M. Kerr, and G. R. Stark. 1994. Jak-STAT pathways and transcriptional activation in response to IFNs and other extracellular signaling proteins. Science 264:1415-1421.

98. Moore, K. W., R. de Waal Malefyt, R. L. Coffman, and A. O'Garra. 2001. Interleukin-10 and the interleukin-10 receptor. Annu Rev Immunol 19:683-765.

99. Aman, M. J., T. Tretter, I. Eisenbeis, G. Bug, T. Decker, W. E. Aulitzky, H. Tilg, C. Huber, and C. Peschel. 1996. Interferon-alpha stimulates production of interleukin-10 in activated CD4+ T cells and monocytes. Blood 87:4731-4736. 
100. Porrini, A. M., D. Gambi, and A. T. Reder. 1995. Interferon effects on interleukin-10 secretion. Mononuclear cell response to interleukin-10 is normal in multiple sclerosis patients. $J$ Neuroimmunol 61:27-34.

101. Chang, E. Y., B. Guo, S. E. Doyle, and G. Cheng. 2007. Cutting edge: involvement of the type I IFN production and signaling pathway in lipopolysaccharide-induced IL-10 production. J Immunol 178:6705-6709.

102. Wang, X., M. Chen, K. P. Wandinger, G. Williams, and S. Dhib-Jalbut. 2000. IFN-beta- $1 b$ inhibits IL-12 production in peripheral blood mononuclear cells in an IL-10-dependent mechanism: relevance to IFN-beta- $1 b$ therapeutic effects in multiple sclerosis. J Immunol 165:548-557.

103. McRae, B. L., B. A. Beilfuss, and G. A. van Seventer. 2000. IFN-beta differentially regulates CD40-induced cytokine secretion by human dendritic cells. J Immunol 164:23-28.

104. Byrnes, A. A., X. Ma, P. Cuomo, K. Park, L. Wahl, S. F. Wolf, H. Zhou, G. Trinchieri, and C. L. Karp. 2001. Type I interferons and IL-12: convergence and cross-regulation among mediators of cellular immunity. Eur J Immunol 31:20262034.

105. Markowitz, C. E. 2007. Interferon-beta: mechanism of action and dosing issues. Neurology 68:S8-11.

106. Takeda, K., and S. Akira. 2005. Toll-like receptors in innate immunity. Int Immunol 17:1-14.

107. Horng, T., G. M. Barton, R. A. Flavell, and R. Medzhitov. 2002. The adaptor molecule TIRAP provides signalling specificity for Toll-like receptors. Nature $420: 329-333$

108. Horng, T., G. M. Barton, and R. Medzhitov. 2001. TIRAP: an adapter molecule in the Toll signaling pathway. Nat Immunol 2:835-841.

109. Yamamoto, M., S. Sato, H. Hemmi, H. Sanjo, S. Uematsu, T. Kaisho, K. Hoshino, O. Takeuchi, M. Kobayashi, T. Fujita, K. Takeda, and S. Akira. 2002. Essential role for TIRAP in activation of the signalling cascade shared by TLR2 and TLR4. Nature 420:324-329.

110. Medzhitov, R., P. Preston-Hurlburt, E. Kopp, A. Stadlen, C. Chen, S. Ghosh, and C. A. Janeway, Jr. 1998. MyD88 is an adaptor protein in the hToll/IL-1 receptor family signaling pathways. Mol Cell 2:253-258.

111. Martin, M., R. E. Schifferle, N. Cuesta, S. N. Vogel, J. Katz, and S. M. Michalek. 2003. Role of the phosphatidylinositol 3 kinase-Akt pathway in the regulation of IL-10 and IL-12 by Porphyromonas gingivalis lipopolysaccharide. J Immunol 171:717-725. 
112. Hu, X., P. K. Paik, J. Chen, A. Yarilina, L. Kockeritz, T. T. Lu, J. R. Woodgett, and L. B. Ivashkiv. 2006. IFN-gamma suppresses IL-10 production and synergizes with TLR2 by regulating GSK3 and CREB/AP-1 proteins. Immunity 24:563-574.

113. Rodionova, E., M. Conzelmann, E. Maraskovsky, M. Hess, M. Kirsch, T. Giese, A. D. Ho, M. Zoller, P. Dreger, and T. Luft. 2007. GSK-3 mediates differentiation and activation of proinflammatory dendritic cells. Blood 109:1584-1592.

114. Cross, D. A., A. A. Culbert, K. A. Chalmers, L. Facci, S. D. Skaper, and A. D. Reith. 2001. Selective small-molecule inhibitors of glycogen synthase kinase-3 activity protect primary neurones from death. $J$ Neurochem 77:94-102.

115. Stambolic, V., and J. R. Woodgett. 1994. Mitogen inactivation of glycogen synthase kinase- 3 beta in intact cells via serine 9 phosphorylation. Biochem $J 303$ (Pt 3):701-704.

116. Panne, D., T. Maniatis, and S. C. Harrison. 2007. An atomic model of the interferon-beta enhanceosome. Cell 129:1111-1123.

117. Morton, S., R. J. Davis, A. McLaren, and P. Cohen. 2003. A reinvestigation of the multisite phosphorylation of the transcription factor c-Jun. EMBO J 22:38763886.

118. Wei, W., J. Jin, S. Schlisio, J. W. Harper, and W. G. Kaelin, Jr. 2005. The v-Jun point mutation allows c-Jun to escape GSK3-dependent recognition and destruction by the Fbw7 ubiquitin ligase. Cancer Cell 8:25-33.

119. Smeal, T., B. Binetruy, D. A. Mercola, M. Birrer, and M. Karin. 1991. Oncogenic and transcriptional cooperation with Ha-Ras requires phosphorylation of c-Jun on serines 63 and 73. Nature 354:494-496.

120. Kawai, T., O. Adachi, T. Ogawa, K. Takeda, and S. Akira. 1999. Unresponsiveness of MyD88-deficient mice to endotoxin. Immunity 11:115-122.

121. Takahasi, K., T. Fujita, and F. Inagaki. 2004. [Three dimensional structure of IRF-3 and its implication in signal transduction]. Tanpakushitsu Kakusan Koso 49:1280-1287.

122. Takahasi, K., N. N. Suzuki, M. Horiuchi, M. Mori, W. Suhara, Y. Okabe, Y. Fukuhara, H. Terasawa, S. Akira, T. Fujita, and F. Inagaki. 2003. X-ray crystal structure of IRF-3 and its functional implications. Nat Struct Biol 10:922-927.

123. Stockinger, S., B. Reutterer, B. Schaljo, C. Schellack, S. Brunner, T. Materna, M. Yamamoto, S. Akira, T. Taniguchi, P. J. Murray, M. Muller, and T. Decker. 2004. IFN regulatory factor 3-dependent induction of type I IFNs by intracellular bacteria is mediated by a TLR- and Nod2-independent mechanism. I Immunol $173: 7416-7425$. 
124. Santini, S. M., T. Di Pucchio, C. Lapenta, S. Parlato, M. Logozzi, and F. Belardelli. 2002. The natural alliance between type I interferon and dendritic cells and its role in linking innate and adaptive immunity. J Interferon Cytokine Res 22:1071-1080.

125. Goh, K. C., S. J. Haque, and B. R. Williams. 1999. p38 MAP kinase is required for STAT1 serine phosphorylation and transcriptional activation induced by interferons. EMBO J 18:5601-5608.

126. Uddin, S., E. N. Fish, D. A. Sher, C. Gardziola, M. F. White, and L. C. Platanias. 1997. Activation of the phosphatidylinositol 3-kinase serine kinase by IFN-alpha. J Immunol 158:2390-2397.

127. Polumuri, S. K., V. Y. Toshchakov, and S. N. Vogel. 2007. Role of phosphatidylinositol-3 kinase in transcriptional regulation of TLR-induced IL-12 and IL- 10 by $\mathrm{Fc}$ gamma receptor ligation in murine macrophages. $J$ Immunol 179:236-246.

128. Jope, R. S., C. J. Yuskaitis, and E. Beurel. 2007. Glycogen synthase kinase-3 (GSK3): inflammation, diseases, and therapeutics. Neurochem Res 32:577-595.

129. Markou, T., T. E. Cullingford, A. Giraldo, S. C. Weiss, A. Alsafi, S. J. Fuller, A. Clerk, and P. H. Sugden. 2008. Glycogen synthase kinases 3alpha and 3beta in cardiac myocytes: regulation and consequences of their inhibition. Cell Signal 20:206-218.

130. Lee, T. P., S. J. Leu, J. C. Huang, Y. C. Song, R. S. Jhou, S. J. Tang, and K. H. Sun. 2008. Anti-ribosomal phosphoprotein autoantibody triggers interleukin-10 overproduction via phosphatidylinositol 3-kinase-dependent signalling pathways in lipopolysaccharide-activated macrophages. Immunology.

131. Uddin, S., B. Majchrzak, J. Woodson, P. Arunkumar, Y. Alsayed, R. Pine, P. R. Young, E. N. Fish, and L. C. Platanias. 1999. Activation of the p38 mitogenactivated protein kinase by type I interferons. J Biol Chem 274:30127-30131.

132. Uddin, S., B. Majchrzak, P. C. Wang, S. Modi, M. K. Khan, E. N. Fish, and L. C. Platanias. 2000. Interferon-dependent activation of the serine kinase PI 3'-kinase requires engagement of the IRS pathway but not the Stat pathway. Biochem Biophys Res Commun 270:158-162.

133. Livak, K. J., and T. D. Schmittgen. 2001. Analysis of relative gene expression data using real-time quantitative PCR and the 2(-Delta Delta $\mathrm{C}(\mathrm{T})$ ) Method. Methods 25:402-408.

134. Welsh, G. I., C. M. Miller, A. J. Loughlin, N. T. Price, and C. G. Proud. 1998. Regulation of eukaryotic initiation factor eIF2B: glycogen synthase kinase-3 phosphorylates a conserved serine which undergoes dephosphorylation in response to insulin. FEBS Lett 421:125-130. 
135. Fiol, C. J., A. M. Mahrenholz, Y. Wang, R. W. Roeske, and P. J. Roach. 1987. Formation of protein kinase recognition sites by covalent modification of the substrate. Molecular mechanism for the synergistic action of casein kinase II and glycogen synthase kinase 3. J Biol Chem 262:14042-14048.

136. Yang, C. H., A. Murti, S. R. Pfeffer, M. Fan, Z. Du, and L. M. Pfeffer. 2008. The role of TRAF2 binding to the type I interferon receptor in alternative NF kappaB activation and antiviral response. $J$ Biol Chem 283:14309-14316.

137. Nagai, T., O. Devergne, T. F. Mueller, D. L. Perkins, J. M. van Seventer, and G. A. van Seventer. 2003. Timing of IFN-beta exposure during human dendritic cell maturation and naive Th cell stimulation has contrasting effects on Th1 subset generation: a role for IFN-beta-mediated regulation of IL-12 family cytokines and IL-18 in naive Th cell differentiation. $J$ Immunol 171:5233-5243.

138. Lande, R., E. Giacomini, T. Grassi, M. E. Remoli, E. Iona, M. Miettinen, I. Julkunen, and E. M. Coccia. 2003. IFN-alpha beta released by Mycobacterium tuberculosis-infected human dendritic cells induces the expression of CXCL10: selective recruitment of NK and activated T cells. J Immunol 170:1174-1182.

139. Heystek, H. C., B. den Drijver, M. L. Kapsenberg, R. A. van Lier, and E. C. de Jong. 2003. Type I IFNs differentially modulate IL-12p70 production by human dendritic cells depending on the maturation status of the cells and counteract IFNgamma-mediated signaling. Clin Immunol 107:170-177.

140. Rep, M. H., H. M. Schrijver, T. van Lopik, R. Q. Hintzen, M. T. Roos, H. J. Ader, C. H. Polman, and R. A. van Lier. 1999. Interferon (IFN)-beta treatment enhances CD95 and interleukin 10 expression but reduces interferon-gamma producing $T$ cells in MS patients. $J$ Neuroimmunol 96:92-100.

141. Wegenka, U. M., N. Dikopoulos, J. Reimann, G. Adler, and C. Wahl. 2007. The murine liver is a potential target organ for IL-19, IL-20 and IL-24: Type I Interferons and LPS regulate the expression of IL-20R2. J Hepatol 46:257-265.

142. Dikopoulos, N., A. Bertoletti, A. Kroger, H. Hauser, R. Schirmbeck, and J. Reimann. 2005. Type I IFN negatively regulates CD8+ T cell responses through IL-10-producing CD4+ T regulatory 1 cells. J Immunol 174:99-109.

143. Florquin, S., Z. Amraoui, D. Abramowicz, and M. Goldman. 1994. Systemic release and protective role of IL-10 in staphylococcal enterotoxin B-induced shock in mice. J Immunol 153:2618-2623.

144. Jansen, P. M., T. C. van der Pouw Kraan, I. W. de Jong, G. van Mierlo, J. Wijdenes, A. A. Chang, L. A. Aarden, F. B. Taylor, Jr., and C. E. Hack. 1996. Release of interleukin-12 in experimental Escherichia coli septic shock in baboons: relation to plasma levels of interleukin-10 and interferon-gamma. Blood 87:5144-5151. 
145. Gerard, C., C. Bruyns, A. Marchant, D. Abramowicz, P. Vandenabeele, A. Delvaux, W. Fiers, M. Goldman, and T. Velu. 1993. Interleukin 10 reduces the release of tumor necrosis factor and prevents lethality in experimental endotoxemia. $J \operatorname{Exp} \operatorname{Med}$ 177:547-550.

146. Iwasaki, A., and R. Medzhitov. 2004. Toll-like receptor control of the adaptive immune responses. Nat Immunol 5:987-995.

147. Mantovani, A., C. Garlanda, M. Locati, T. V. Rodriguez, S. G. Feo, B. Savino, and A. Vecchi. 2007. Regulatory pathways in inflammation. Autoimmun Rev 7:811.

148. Guerau-de-Arellano, M., and B. T. Huber. 2005. Chemokines and Toll-like receptors in Lyme disease pathogenesis. Trends Mol Med 11:114-120.

149. Ulevitch, R. J., and P. S. Tobias. 1995. Receptor-dependent mechanisms of cell stimulation by bacterial endotoxin. Annu Rev Immunol 13:437-457.

150. Asadullah, K., W. Sterry, and H. D. Volk. 2003. Interleukin-10 therapy--review of a new approach. Pharmacol Rev 55:241-269.

151. Schaefer, A., C. Unterberger, M. Frankenberger, M. Lohrum, K. J. Staples, T. Werner, H. Stunnenberg, and L. Ziegler-Heitbrock. 2009. Mechanism of Interferon-gamma mediated down-regulation of Interleukin-10 gene expression. Mol Immunol 46:1351-1359.

152. Mosser, D. M., and X. Zhang. 2008. Interleukin-10: new perspectives on an old cytokine. Immunol Rev 226:205-218.

153. Lambert, S. L., and O. M. Martinez. 2007. Latent membrane protein 1 of EBV activates phosphatidylinositol 3-kinase to induce production of IL-10. $J$ Immunol 179:8225-8234.

154. Garcia, C. A., M. R. Benakanakere, P. Alard, M. M. Kosiewicz, D. F. Kinane, and M. Martin. 2008. Antigenic experience dictates functional role of glycogen synthase kinase-3 in human CD4+ T cell responses. J Immunol 181:8363-8371. 


\section{CURRICULUM VITAE}

Name: Huizhi Wang

Place of Birth: Luo Yang, Henan Province, China

Date of Birth: April 23, 1975

\section{Present address}

Huizhi Wang

501 South Preston Street, School of Dentistry, Room 211B

University of Louisville, Louisville, KY, 40202

Tel: (502)-852-1589

E-mail: hhwang01(agwise louisville.cdu or liaowhuizhi(ayahoo.com.cn

\section{Education}

Sep,2005 present, Ph.D graduate student, Department of Microbiology and Immunology, Oral Health and Systemic Disease Research Group, University of Louisville, Louisville, KY 40202, USA.

Sep,1998 Jul,2001 Department of Molecular pathogeny and microbiology, Zhengzhouuniversity, China Medicine Master Degree was awarded on Jul, 2001

Sep,1993 Jul, 1998 Department of Preventive medicine, Henan medical university, China, Medicine Bachelor degree Awarded on July 1998.

\section{Employment}

Sep,2004 Aug,2005 Technician support Invitrogen Corporation (Carlsbad, CA, U.S.A), Shanghai Aug, 2001 Sep, 2004, Research Associate

State Key Laboratory of Molecular Biology, Institute of Biochemistry and Cell Biology, 
Shanghai Institutes for Biological Sciences, Chinese Academy of Sciences, Shanghai, China

\section{Honors and Awards}

Aug, 2001, The "First-class medical and sanitary science award of Henan province" for my dissertation

Jun, 2000, The "Federal medical scholarship and a medal for the top $10 "$

Oct,1999, The "First Class Medical knowledge Service for community"

Mar, 1998, Henan medical university First-class scholarship.

\section{Research Expericences:}

1. Research in Ph.D. Graduate Study:

Identifying and characterizing the critical components of cell signaling pathways regulating host inflammatory responses, specifically, exploring the functional role of glycogen synthase kinase 3 (GSK3), the downstream constitutive activate serine/threonine kinase of PI3K pathway, in the innate immune responses and evaluating its therapeutic efficacy that could attenuate the inflammation disease in vivo. Our laboratory has identified GSK3 $\beta$ as a central regulator of the inflammatory process by its ability to differentially regulate the levels of pro- and anti-inflammatory cytokines upon TLR activation. My work focuses on the regulatory role of GSK3- $\beta$ to the TLR4-induced type I interferon as well as the interferon beta induced prototypical immunosuppressive cytokine, IL-10. Given the pivotal role of GSK3 $\beta$ in the TLR induced inflammatory immune response, I am also interested in the crosstalk of GSK3-CREB pathway to other classical inflammation related pathway like mTORC1 and beta-catenin pathways. From I joined in this lab to now, I have finished two projects and the third one is on going.

(1). IFN- $\beta$ production induced by TLR4 is negatively regulated by GSK3- $\beta$

(2). Functional role of GSK3 $\beta$ in IFN- $\beta$ induced IL-10 production 
(3). GSK $3 \beta$ regulates the mTOR-mediated inflammatory response in TLR-stimulated innate immune cells

2. As a research assocaite in Institute of Biochemistry and Cell Biology, Shanghai, I am mainly responsible for and have finished three projects:

(1). The application of Nanocrystal Quantum Dots in the cell biology and diagnosis. Given several advantages of Quantum Dots including higher quantum yield, exceptional photo-stability, a narrow, tunable, and symmetric emission spectrum, we determine whether it can be used as a novel fluorescent probe to labeling some cell molecules in vitro and in vivo. By using Quantum Dots with emission wavelength 605 (QD605) to label tumor marker CA125, we found the exceptional photo-property of QDs to label the bio-molecule in various specimens which suggested QDs might be used extensively in bio-detecting and clinical diagnosis as a novel fluorescent probe.

(2). Improvement the technique of protein-microarray and development the secondary generation of bio-microarry including microRNA-array, high thought DNA-array. Investigating the application of Quantum dots in the multiple channels of SPR platform and subsequently enhances the signal/noise ratio and expand its application in the cell biology.

(3). Use fluorescence resonance energy transfer (FRET) and hydrostatic pressure to explore the principle of protein folding/unfolding in some disease conditions like early phase of Alzheimer.

3. As a biology master candidate, from Jul.1998 2001, , finishing the project named "cloning and expression of $31 \mathrm{kDa}$ structure gene in pre-cyst trichinella" which provided me much experience on various basic molecular biology techniques such as RNA extraction, real time-PCR, cloning and expression, Mutagenesis, Cell culture, 
Immunochemistry and ISH, Western-blot and Protein purification. Additionally, other collaboration projects provide me many chances to familiar with many techniques on mice work.

\section{PUBLICATIONS}

1. Wang H, Garcia CA, Alard P, Mitchell T, Kinane DF, Martin M. GSK $3 \beta$ regulates the mTOR-mediated inflammatory response in TLR-stimulated innate immune cells (in prepration)

2. Garcia CA, Wang H, Benakanakere, M.R., Kinane DF, Martin M. Inhibition of GSK3-b in human CD4+ memory T cells promotes IL-10 production upon IL12 stimulation. (Submitted)

3. Wang H, Benakanakere, M.R., Garcia CA, Kinane DF, Martin M. Interferon beta (IFN- $\beta$ )-induced IL-10 production in human Monocyte-derived Dendritic cells was negatively regulated by Glycogen Synthase Kinase 3-beta (GSK3- $\beta$ ) (Submitted)

4. Wang H, Garcia CA, Rehani K, Cekic C, Alard P, Kinane DF, Alard P, Mitchell T, Martin M. IFN-beta production by TLR4-stimulated innate immune cells is negatively regulated by GSK3-beta. J Immunol. 2008 Nov 15;181(10):6797-802.

5. Wang H, Rehani K, Garcia CA, Kinane DF, Martin M. Toll-like receptormediated production of IL-1Ra is negatively regulated by GSK3 via the MAPK ERK1/2, J Immunol, 2009,Jan 1;182(1):547-53 (Co-first author)

6. Rehani K, Scott DA, Renaud D, Hamza H, Williams LR, Wang H, Martin M. Cotinine-induced convergence of the cholinergic and PI3 kinase-dependent antiinflammatory pathways in innate immune cells. Biochim Biophys Acta. 2008 Mar;1783(3):375-82.

7. Wang H, Liang RQ, Wang HY, Ruan KC. Detection of tumor marker CA 125 in ovarian carcinoma using quantum dots. Acta Biochim Biophys Sin, 2004 Oct; 36 (10): $681-6$

8. Wang $\mathbf{H}$, Wang ZQ, Cui $J$. Application research of recombinant antigen on immune diagnoses and immune prophylaxis of Trichinosis. Chinese Journal of Zoonoses,2002,18(6):96-98 
9. Cui J, Wang ZQ, Wang H, Zhao GQ, Zhang HW etc. Cloning and Expression of the Antigen Structural Gene TspE1 from Pre-encysted Larvae of Trichinella spiralis. Chin J Parasitol Parasit Dis, 2002,20(5):278-280

10. Cui J, Zhao GQ, Wang H, Zhang HW etc. Cloning and sequencing of the gene encoding a $31 \mathrm{kDa}$ antigen of Trichinella spiralis pre-encysted larvae. Chinese Journal of Zoonoses, 2002,18(5):37-41

11. Cui J, Wang ZQ, Wang $\mathbf{H}$, etc. Molecular cloning and genetic polymorphism analysis of TspE1 gene of Henan isolates of Trichinella spiralis. Journal of Zhengzhou university (Medical Sciences), 2002, 37(3):295-300

12. Cui J, Wang ZQ, Zhang RG, Wang $\mathbf{H}$,etc. Research of Trichinosis on epidemiology, clinic medicine, serumology and molecular biology. Henan Medicine Research, 2002,11(1):347-348 